WellBeing International

WBI Studies Repository

2008

\title{
Non-Animal Methodologies within Biomedical Research and Toxicity Testing
}

Andrew Knight

Animal Consultants International

Follow this and additional works at: https://www.wellbeingintlstudiesrepository.org/acwp_arte

Part of the Bioethics and Medical Ethics Commons, Laboratory and Basic Science Research Commons, and the Research Methods in Life Sciences Commons

\section{Recommended Citation}

Knight, A. (2008). Non-animal methodologies within biomedical research and toxicity testing. Altex, 25(3), 213-231.

This material is brought to you for free and open access by WellBeing International. It has been accepted for inclusion by an authorized administrator of the WBI Studies Repository. For more information, please contact wbisr-info@wellbeingintl.org.

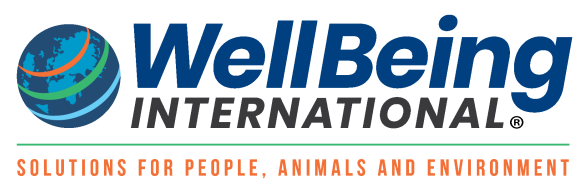




\section{Non-Animal Methodologies within Biomedical Research and Toxicity Testing}

\author{
Andrew Knight \\ Animal Consultants International, London, UK
}

\section{Summary}

Laboratory animal models are limited by scientific constraints on human applicability, and increasing regulatory restrictions, driven by social concerns. Reliance on laboratory animals also incurs marked - and in some cases, prohibitive - logistical challenges, within high-throughput chemical testing programmes, such as those currently underway within Europe and the US. However, a range of non-animal methodologies is available within biomedical research and toxicity testing. These include: mechanisms to enhance the sharing and assessment of existing data prior to conducting further studies, and physicochemical evaluation and computerised modelling, including the use of structure-activity relationships and expert systems. Minimally-sentient animals from lower phylogenetic orders or early developmental vertebral stages may be used, as well as microorganisms and higher plants. A variety of tissue cultures, including immortalised cell lines, embryonic and adult stem cells, and organotypic cultures, are also available. In vitro assays utilising bacterial, yeast, protozoal, mammalian or human cell cultures exist for a wide range of toxic and other endpoints. These may be static or perfused, and may be used individually, or combined within test batteries. Human hepatocyte cultures and metabolic activation systems offer potential assessment of metabolite activity and organ-organ interaction. Microarray technology may allow genetic expression profiling, increasing the speed of toxin detection, well prior to more invasive endpoints. Enhanced human clinical trials utilising microdosing, staggered dosing, and more representative study populations and durations, as well as surrogate human tissues, advanced imaging modalities and human epidemiological, sociological and psychological studies, may increase our understanding of illness aetiology and pathogenesis, and facilitate the development of safe and effective pharmacologic interventions. Particularly when human tissues are used, non-animal models may generate faster, cheaper results, more reliably predictive for humans, whilst yielding greater insights into human biochemical processes. Greater commitment to their development and implementation is necessary, however, to efficiently meet the needs of high-throughput chemical testing programmes, important emerging testing needs, and the ongoing development of human clinical interventions.
Zusammenfassung: Versuchstierfreie Methoden in der biomedizinischen Forschung und Toxizitätsprüfung

Tierversuche werden durch wissenschaftliche Einschränkungen und wachsende regulatorische Restriktionen, welche durch soziale Bedenken angetrieben werden, limitiert. Die Abhängigkeit von Labortieren führt auch zu deutlichen - und in manchen Fällen prohibitiven - logistischen Herausforderungen innerhalb von Hochdurchsatztestverfahren, wie sie momentan in Europa und den USA durchgefiihrt werden. Dennoch steht eine Ansammlung von tierfreien Methoden für die biomedizinische Forschung und die Toxizitätsprüfung zur Verfügung. Diese schließt ein: Mechanismen, welche die Einsicht und Bewertung von vorliegenden Daten vor der Durchfiihrung neuer Studien fördern können, und physikochemische Analysen und Computer-gestützte Modellierung, einschließlich Struktur-Wirkungs-Beziehungen und Expertensystemen. Minimal empfindungsfähige Tiere niederer phylogenetischer Ordnungen oder früher Entwicklungsstadien von Vertebraten können genutzt werden, sowie Mikroorganismen und höhere Pflanzen. Eine Vielfalt an Gewebekulturen, einschließlich immortalisierter Zelllinien, embryonaler und adulter Stammzellen und organotypischer Kulturen stehen zur Verfügung. In vitro Tests, welche auf Kulturen von Bakterien-, Hefe-, Protozoen-, Säuger- oder menschlichen Zellen beruhen, sind für die Erfassung einer breiten Palette toxischer oder anderer Endpunkte entwickelt worden. Diese Kulturen können statisch oder perfundiert sein und können individuell oder in Kombination innerhalb von Testbatterien durchgefïhrt werden. Humane Hepatozytenkulturen und metabolische Aktivierungssysteme bieten die Möglichkeit, auch die Aktivität der Metaboliten zu untersuchen. Die Microarray-Technologie könnte die Erfassung genetischer Expressionsmuster erlauben, wodurch die Erkennung von Toxinen schneller erfolgen könnte, bereits vor der Erfassung invasiver Endpunkte. Ausgefeilte klinische Studien am Menschen, welche von Mikrodosierung, abgestufter Dosierung und besser repräsentativen Kohorten und Studiendauern sowie von Surrogatgeweben Gebrauch machen, aktuelle bildgebende Verfahren und epidemiologische, soziologische und psychologische Studien am Menschen könnten unser Verständnis der Ätiologie von Erkrankungen und ihrer Pathogenese erweitern und die Entwicklung von sicheren und wirkungsvollen pharmakologischen Interventionen erleichtern. Insbesondere könnten durch Nutzung menschlicher Zellen und Gewebe in tierfreien Modellen schneller und billiger Ergebnisse erzielt werden, welche verlässlicher die Wirkung im Menschen vorhersagen könnten, während sie neue Einsichten in menschliche biochemische Prozesse liefern würden. Eine stärkere Verpflichtung zur Entwicklung und Implementierung solcher Modelle ist jedoch von Nöten, um effizient die Anforderungen von Hochdurchsatz-Chemikalientestprogrammen, neu entstehenden Testbedürfnissen und der Entwicklung klinischer Interventionen zu decken.

Keywords: 3Rs, alternative, animal experimentation, animal model, toxicity testing, biomedical research

Received $8^{\text {th }}$ March 2008; received in final form and accepted for publication $10^{\text {th }}$ June 2008 


\section{Introduction}

\subsection{Limitations incurred by animal models}

\subsubsection{Logistical limitations}

Worldwide, millions of animals have been used in toxicity testing and biomedical research aimed at developing cures for human diseases. Based on publication rates, Taylor and colleagues (2008) estimated that 58.3 million living non-human vertebrates were subjected to fundamental or medically-applied biomedical research, toxicity testing, or educational use, within 179 countries, in 2005. When animals killed for the provision of experimental tissues, used to maintain established genetically-modified strains, or bred for laboratory use but killed as surplus to requirements, were included, the estimate increased to a total of approximately 127 million non-human vertebrates worldwide (Knight, 2008). Due to several factors, however, these estimates were considered to be highly conservative.

Additionally, large increases in laboratory animal use have recently been proposed within several chemical testing programmes intended to rectify knowledge gaps regarding the toxicity of chemicals produced or imported into Europe or the United States in particularly high quantities, or that otherwise raise special concerns (Combes et al., 2004; Green and Goldberg, 2004). Such programmes follow increasing public, political and regulatory concern about the potential toxicity of a wide range of environmental, occupational and consumer chemicals.

Prominent among these programmes is the 2003 Commission of the European Communities (EC) proposal for the Registration, Evaluation and Authorisation of Chemicals (REACH), which entered into force on $1^{\text {st }}$ June, 2007. REACH aims to assess the toxicity of some 30,000 chemicals produced or imported into the European Union (EU) in excess of one metric ton annually (Fenner-Crisp et al., 2000; Green et al., 2001; Charles, 2004; Stokes, 2004; Louekari et al., 2006).

The testing requirements of $\mathrm{REACH}$ are unprecedented. Reproductive and developmental toxicity data, for example, are required for all substances manufac- tured or imported in quantities in excess of 10 metric tons annually. It has been estimated that reliance on traditional whole animal testing could require the use of almost 22 million vertebrate animals to meet such data requirements, at a cost of up to several hundred thousand dollars per registered substance - although total animal numbers may reportedly be reduced to 10 million or lower, if proprietary in-house toxicity data and appropriate non-animal testing and evaluation methodologies are utilised (Scialli, 2008).

Within the US, two noteworthy programmes have been managed by the Environmental Protection Agency (EPA) since 1998. The High Production Volume (HPV) Challenge Programme targets chemicals produced or imported in quantities in excess of 1 million pounds annually. As of June 2007, data on 4,460 chemicals had been supplied or was being gathered (EPA, 2008). The Endocrine Disrupting Chemicals Research Program (EDCs Research Program) aims to assess dietary and environmental chemicals with the potential to disrupt the normal hormonal milieu within humans and wildlife. In 1998, the EPA's Endocrine Disruptor Screening and Testing Advisory Committee recommended a tiered testing approach for the evaluation of oestrogen, androgen and thyroid-related effects of some 87,000 commercial chemicals and environmental contaminants (Charles, 2004).

The logistical challenges incurred through reliance on traditional animal bioassays to meet such unprecedented testing demands are aptly demonstrated by the traditional rodent carcinogenicity bioassay. This assay takes upwards of two years to produce results of demonstrably poor human specificity (Knight, et al., 2006b), at an average cost of $€ 780,000$ (Fleischer, 2007; see also Combes et al., 2007). Unsurprisingly, by 1998 , only about $2,000(2.7 \%)$ of the 75,000 industrial chemicals then in use and listed within the EPA Toxic Substances Control Act inventory had been tested for carcinogenicity (Epstein, 1998). The resources consumed by testing just these $2.7 \%$ of industrial chemicals included hundreds of millions of US dollars (Conolly et al., 1988), millions of skilled personnel hours
(Gold et al., 1999), and millions of animal lives (Monro and MacDonald, 1998; Gold et al., 1999).

As stated by Bremer and colleagues (2007), requiring in vivo testing for every adverse effect within these high-throughput chemical testing programmes would exceed the capacity of available scientific facilities and expertise, result in unacceptably high false positive rates, and, in all likelihood, endanger the success of these programmes.

Such considerations have generated a strong interest in alternative testing strategies. This interest was further increased when challenging timelines for phasing out animal testing of cosmetics, as well as marketing bans on cosmetics tested in vivo after certain chronological deadlines were imposed within the EU under the seventh Amending Directive 2003/15/ EC to Cosmetics Directive 76/768/EEC (Combes et al., 2007; Lilienblum et al., 2008).

\subsubsection{Scientific limitations}

The scientific limitations incurred through modelling humans by animals within fundamental or clinically-applied research and toxicity testing are considerable, wide-ranging, and increasingly recognised. These may include differences between species and genders - with subsequent effects on toxico- and pharmacokinetics ( $P K$ : the study of bodily distribution, particularly $A D M E$ : absorption, distribution, metabolism and excretion), or pharmacodynamics ( $P D$ : the study of mechanisms of action, and drug effects). They commonly include the use of unrealistic doses and exposure durations; the loss of biological variability or predictivity, resulting from the use of in-bred strains, young animals, restriction to single genders, and inadequate group sizes; the lack of co-morbidities or other human risk factors; and stress-related physiological or immunological distortions, among others (Hartung, 2008a,b; Matthews, 2008).

Interspecies variations in P450-dependent monooxygenases are well established (Guengerich, 2006). These constitute the major family of xenobiotic metabolising enzymes - that is, enzymes catalysing the 
oxidation (i.e., the metabolism) of foreign compounds, such as drugs or toxins. Their major purpose is the generation of nontoxic blood-soluble metabolites suitable for renal or other elimination. Interspecies differences in metabolic pathways, rates and products, may decrease efficacy or produce toxicity, and are a key cause of high clinical trial failure rates during pharmaceutical development (DiMasi et al., 2003). In fact, only $8 \%$ of all drugs progressing to human trials after demonstration of safety in animal studies gain FDA licensing approval (Pippin, 2008).

The utility of animal models has been repeatedly questioned. Of 20 published systematic reviews examining human clinical utility located during a recent, comprehensive search, animal models demonstrated significant potential to contribute toward the development of clinical interventions in only two cases, one of which was contentious. Seven additional reviews failed to demonstrate utility in reliably predicting human toxicological outcomes, such as carcinogenicity and teratogenicity. Results in animal models were frequently equivocal, or inconsistent with human outcomes (Knight, 2007).

A European working group comprised of 18 pharmaceutical companies recently conducted an evidence-based review of the value of acute toxicity studies conducted on 74 compounds. Such animalbased studies - which are usually conducted in rodents - have been required prior to the licensing of pharmaceuticals intended for human use. This is the only study type during the process in which lethality is mentioned as an endpoint (Robinson et al., 2008).

However, the acute toxicity data for these 74 compounds was never used to: (i) terminate drugs from development, (ii) support dose selection for subsequent repeat-dose animal studies, or (iii) set doses, identify target organs, or indicate biomarkers for monitoring in human clinical trials - a minority of which also occurred prior to animal studies. The conclusions - which were discussed and agreed with representatives of regulatory bodies from the US, Japan and Europe, in 2006 - were that such studies are not necessary prior to first clinical trials in humans, and that sufficient information can be obtained from other studies conducted at more relevant doses for humans, which already comprise an integral part of drug development (Robinson et al., 2008).

\subsubsection{Regulatory limitations}

Increasing social concern about invasive animal use within biomedical research and toxicity testing has driven the evolution of related legislation and regulatory policies within many countries and regions (for summaries see: http://www. vetmed.ucdavis.edu/Animal_Alternatives/ policies\&regs.html).

In 1986, the Council of Europe, European Treaty Series No. 123 (ETS 123) on the European Convention for the Protection of Vertebrate Animals used for Experimental and Other Scientific Purposes, was developed. It requires the consideration of non-animal methods (if reasonably and practicably available), or justification of animal use, in which case minimum numbers are required, with minimisation of pain, suffering or lasting harm (Council of Europe, 1986).

Similarly, the 1986 European Directive 86/609/EEC on the Protection of Animals used for Experimental and Other Scientific Purposes states that: "An experiment shall not be performed, if another scientifically satisfactory method of obtaining the result sought, not entailing the use of an animal, is reasonably and practicably available." [Article 7.2]. And further, that: "The Commission and Member States should encourage research into the development and validation of alternative techniques which could provide the same level of information as that obtained in experiments using animals but which involve fewer animals or which entail less painful procedures, and shall take such other steps as they consider appropriate to encourage research in this field." [Article 23.1] (Leist et al., 2008b). Such Directives are legally binding on all EU member states (Kulpa-Eddy, 2006).

Within the US, the regulations associated with the Animal Welfare Act (AWA, 1966, most recently amended in 1990) require documented consideration of alternatives, "to any procedure that would reasonably be expected to cause more than slight or momentary pain or distress in a human being." Warm-blooded vertebrates are protected, with some exceptions - primarily birds, mice and rats (despite the fact that these rodent species comprise the overwhelming majority of laboratory animals). Such consideration is required whether or not analgesics or anaesthetics are used, and research must not unnecessarily duplicate previous experiments (US Government Printing Office, 1985; Kulpa-Eddy, 2006; Larson, 2006).

Unfortunately, however, alternatives must only be considered within the US The AWA does not actually require their use, even when scientifically validated. Accordingly, a 2007 Petition to the US Food and Drug Administration for [the] Mandatory Use of Non-Animal Methods, filed by a coalition of animal protection and other organisations, and individual scientists, seeks changes in Food and Drug Administration (FDA) regulations and policies that would require that pharmaceutical companies, device manufacturers and other entities regulated by the FDA submit data only from scientifically satisfactory non-animal test methods, in lieu of corresponding animal-based methods, whenever such alternatives are available (MAP Coalition, 2007; Pippin, 2008). The FDA now requires only human-based in vitro systems for the evaluation of drug-drug interaction potential, with no requirement for animal studies (Li, 2008a).

\subsection{Scientific interest in alternatives}

Increased scientific interest in non-animal alternatives has been reflected by their ongoing development and formal validation, and by the establishment of several international centres and university departments dedicated to this work (Leist et al., 2008a). In 1981 a Center for Alternatives to Animal Testing was established at the John Hopkins University Bloomberg School of Public Health, to support the creation, development, validation and use of alternatives to animals, in research, product safety testing and education. In 2004 the British government established the National Centre for the Replacement, Reduction and Refinement of Animals in Research, whose ultimate aim is the replacement of all animal ex- 
periments. Similar centres exist in Germany, Austria, the Netherlands and Japan. Between 1998 and 2007, 24 distinct tests or categories of test methods that could replace, reduce or refine laboratory animal use were scientifically validated and registered with the European Centre for the Validation of Alternative Methods (ECVAM), an EC organisation. Thirteen had achieved regulatory acceptance (ECVAM, n.d.).

In 2008 a partnership was announced between the US National Institutes of Health (NIH) Chemical Genomics Center of the National Human Genome Research Institute, the National Institute of Environmental Health Sciences, and the EPA (Collins et al., 2008; Hartung and Leist, 2008; Leist et al., 2008b). The partnership aims to meet the future toxicity testing needs of the EPA and the National Toxicology Program (NTP) by implementing recommendations proposed in the NTP's Roadmap for the Future (NTP, 2004), and the report of the National Research Council's Committee on Toxicity Testing and Assessment of Environmental Agents, Toxicity Testing in the $21^{\text {st }}$ Century: A Vision and a Strategy (NRC, 2007). These reports propose significantly increased roles for non-animal alternatives, such as high-throughput robotic molecular and cellular screening methods. They estimate, for example, that running 1,408 chemicals through 200 protein and cell-based assays, at fifteen different concentrations, would take about two and a half weeks, and cost around USD 1 million.

\subsection{Scientific resistance to alternatives}

However, resistance to the use of alternatives remains considerable, within some governmental, academic and commercial sectors. A 2000 survey identified a range of common areas of non-compliance of US researchers with the regulations associated with the AWA. The most common was inadequate consideration of alternatives (at 600-800 research facilities), and the fourth most common was unnecessary experimental duplication (at approximately 250 facilities). Other deficiencies identified included inadequate justification for animal numbers, and alleged uncertainty of research personnel about signs indicative of pain and/or distress (USDA-APHIS-AC, 2000).

Similarly, chemical companies submitting HPV test plans to the EPA have often failed to follow even the minimal guidance provided by the EPA about alternatives. They have failed to use existing published data individually, or in conjunction with other data (in a weightof-evidence approach - which aims to review all available, relevant evidence, in a structured, systematic, independent and transparent manner (Balls and Combes, 2006)); and have failed to avoid duplicative or otherwise unnecessary animal testing. They have proposed irrelevant tests (such as acute fish toxicity tests on water-insoluble chemicals), or tests clearly unnecessary to meet HPV requirements. Opportunities to use replacement assays, such as in vitro genotoxicity tests, have been ignored, and companies have failed to take advantage of opportunities to combine protocols, sometimes doubling the number of animals killed. In its responses to such test plan proposals, the EPA frequently failed to encourage companies to follow basic animal welfare principles (Sandusky et al., 2006).

Such attitudes toward biomedical animal use reveal a marked lack of consideration of scientific constraints on the utility of animal models for human applications, of social concerns about their use, and about the unprecedented logistical challenges that reliance on animal models will inevitably incur, during high-throughput chemical testing programmes. They also demonstrate marked and widespread deficiencies in awareness of the potential and availability of non-animal methods.

Accordingly, for those less familiar with the alternatives field, this review seeks to broadly illustrate the potential offered by non-animal (replacement) methodologies, through examination of selected examples. As stated by Gruber and Hartung (2004): “Availability and awareness of adequate in vitro techniques represent the prerequisites for the use of alternative methods," although alternatives are not limited solely to in vitro methodologies.

This review does not seek to definitively cover any particular sub-discipline within the sizeable alternatives field, or to review refinement or reduction strategies, which have often been well covered else- where (e.g. Brown et al., 1995; Morton, 1995, 1998; Rowan, 1995; Pellizzer et al., 2005; Luttun and Verfaillie, 2006).

\section{Discussion}

\subsection{Alternatives to laboratory animal use}

The three Rs (3Rs) of replacement (with non-animal models), reduction (of animal numbers), and refinement (to decrease animal suffering) of laboratory animal use were first proposed by Russell and Burch (1959), and have since become almost universally accepted as fundamental to good laboratory animal practice (e.g. United States Department of Agriculture (USDA) Policy 12, 2000). As stated by Russell and Burch, "Refinement is never enough, and we should always seek further reduction and if possible replacement. ... Replacement is always a satisfactory answer." A broad range of investigative tools exist that may potentially replace sentient animal use within biomedical research and toxicity testing.

\subsection{Sharing and assessment of existing data}

The first step in any toxicological evaluation of a compound, or the commencement of any biomedical research project, should be a comprehensive and critical assessment of all existing data, in order to determine which, if any, remaining experiments are necessary. To maximise commercial competitiveness, much existing data remains excluded from the public domain within pharmaceutical and chemical company files. However, such exclusion is contrary to the public interest when toxicity data regarding the components of new pharmaceutical or consumer products are not disclosed, when animal experiments are repeated, and when product development is slowed, as a result. Accordingly, it is the view of this author that mandatory disclosure of toxicity data should be legislated after a short-term window (which could be waived in special circumstances) designed to retain a measure of commercial competitiveness and, thereby, incentive for companies that generate new data.

A similar view is shared by European authorities who have made data shar- 
ing mandatory under REACH - both to reduce vertebrate testing, and potential costs incurred by industry through duplicative testing. The REACH guidelines aim to share costs of studies that are already available amongst parties that may benefit through access to resultant data. Where additional testing is deemed necessary, the sharing mechanism aims both to minimise costs and to ensure such testing is conducted only once (ECHA, 2008).

The Carcinogenicity and Genotoxicity eXperience (CGX) database, freely offered on the Internet by the scientific education charity, LHASA Limited (see http://www.lhasalimited.org/index. php?cat=4\&sub_cat=83), provides a large number of published genotoxicity results for rodent carcinogens and noncarcinogens, and provides an example of how such information might be organised and freely shared.

\subsection{Physicochemical evaluation and computerised modelling}

The high costs of drug development have created a strong incentive for the development of tests able to detect deficiencies, such as poor absorption, target organ concentration, clearance or efficacy, and toxicity or other adverse effects, early within the development process. The benefits of modelling and simulation during drug design and pre-clinical assessment can potentially be realised through integration of any available data on physicochemical properties, PK and PD (Balls, 1994; Lavé et al., 2007; Wishart, 2007).

\subsubsection{Biokinetic modelling}

Wishart (2007) recently reviewed available tools for modelling and predicting drug ADME. Such tools include: (1) ADME parameter predictors; (2) metabolic fate predictors; (3) metabolic stability predictors; (4) cytochrome P450 (cP450) substrate predictors, and (5) physiology-based pharmacokinetic (or biokinetic; PBPK or PBBK) modelling software.

PK models predict in vivo concentrations of test substances/metabolites and organ systems affected (Combes et al., 2007). PBPK models utilise both the known anatomy and physiology of the organism (considering properties such as tissue type - e.g. fat vs. muscle, tissue volume, blood flow rates, known active transport or biotransformation pathways), as well as the physicochemical properties of the compound, to estimate the concentration-time relationship of compounds within various body compartments and organ systems (Blaauboer et al., 2006). Such models can be used to predict optimal doses and dosing schedules, potency, and, potentially, level of variability and uncertainty for drug candidates (Wishart, 2007). They may even be used for extrapolation of the biokinetic behaviour of chemicals between different routes of exposure or species (Andersen, 1991; Broadhead and Bottrill, 1997).

Germani and colleagues (2007) provided an example of a PBPK model for predicting the plasma concentration-time curves expected after intravenous administration of candidate drugs to rodents. The predictions were based on a small number of properties that were either calculated based on the structure of the candidate drug (e.g. octanol:water partition coefficient, ionisation constant(s)), or obtained from the typical high-throughput screens implemented in the early drug discovery phases (fraction unbound in plasma, and intrinsic hepatic clearance). Plasma concentration-time curves were predicted with good accuracy.

\subsubsection{Structure-activity relationships}

The relationship between physicochemical structure and biological activity (structure-activity relationship, SAR) was recognised as early as 1894 by Emil Fischer (Nobel Laureate, 1902) - who used the lock-and-key analogy, which may be used to describe the three-dimensional complementarity of drugs with target receptors or enzymes (Vedani et al., 2007a). PD modelling utilises SARs to predict various biological activities on the basis of molecular substructures or other chemical moieties. Quantitative structure activity relationships (QSARs) are mathematical descriptions of the relationships between the physicochemical properties of molecules and their biological activities (Comber et al., 2003), that may be used to predict characteristics at the theoretical, compound design stage (Vedani et al., 2007b).
Due to the large amount of data available for these toxicity endpoints, many in silico models for the prediction of mutagenicity or carcinogenicity exist. Ashby and Tennant (1991) demonstrated that the presence of aromatic amino/nitro-groups, alkylating agents and certain other chemical groups, increased the likelihood of rodent carcinogenesis in a survey of 301 chemicals tested by the NTP. Cronin et al. (2003) described a number of electrophilic molecular substructures common to a range of potential multi-species toxicants. Matthews and Contrera (1998) described the evaluation of a QSAR computerised system that demonstrated $97 \%$ sensitivity for rodent carcinogens, and $98 \%$ specificity for non-carcinogens. The sensitivity of a test is its ability to correctly identify compounds possessing the property of interest (true positives), while the specificity refers to its ability to correctly identify compounds lacking the property of interest (true negatives).

QSARs are often based around models for particular classes of compounds, such as amines and aldehydes (Benigni et al., 2003). Vedani and colleagues (2007b), for example, described their VirtualToxLab, which utilised an advanced QSAR modelling system to predict interactions of drugs and environmental chemicals with receptors mediating endocrinological disruption or other toxicities. The VirtualToxLab offered nine "virtual test kits" for the estrogen $(\alpha / \beta)$, androgen, thyroid $(\alpha / \beta)$, glucocorticoid, aryl hydrocarbon and peroxisome proliferator-activated receptor $\gamma$, as well as for the enzyme cP450 3A4. Tests on 798 compounds predicted binding affinities close to the experimental uncertainty, with only six of 188 test compounds removed by more than a factor of 10 from the experimental binding affinity, and the maximal individual deviation not exceeding a factor of 15 .

Such in silico systems are ideally suited for predicting receptor-mediated toxicity caused by drugs and environmental chemicals. Running VirtualToxLab using contemporary mid-level computer technology allowed prediction of binding affinities for 150 compounds over a weekend. Vedani and colleagues estimated that $60-70 \%$ of the approximately 30,000 chemicals to be re-evaluated within $\mathrm{REACH}$ could be readily processed us- 
ing VirtualToxLab. To improve the applicability and reliability of VirtualToxLab through peer-review, they created a free internet access protocol available to selected laboratories, accessible via admin@biograf.ch.

Such models generally have a strong mechanistic basis and are often userfriendly and easily understood (Combes et al., 2007). They are fast, reproducible and cheap (Vedani et al., 2005). However, their applicability domains are inevitably limited (Combes et al., 2007). As long as some enzyme/receptor systems mediating toxicity remain unknown, false-negative results will inevitably occur (Vedani et al., 2005). QSAR applicability domains will expand as mechanisms and, particularly, receptors mediating additional toxic effects, become known. Improved QSAR models for skin sensitisation, respiratory irritation and genotoxicity, for example, are expected soon (Veith, 2006).

\subsubsection{Expert systems}

Computerised expert systems seek to mimic the judgment of expert toxicologists by using known rules about factors affecting toxicity, in combination with physicochemical or other information about a specific compound. They make predictions about toxicity and related biological outcomes, such as metabolic fate. Gerner and colleagues (2004), for example, described two sets of structural alerts (fragments of chemical structure) for the prediction of skin sensitisation hazard classification, which comprise 15 rules for chemical structures deemed to be sensitising by direct action, and three rules for substructures that act indirectly - i.e. requiring chemical or biochemical transformation. Prevalidation against sensitising chemicals taken from the 'Allergenliste' held by the German Federal Institute for Risk Assessment yielded some reasonable predictivity rates: positive predictivity, $88 \%$; false-positive rate, $1 \%$; specificity, $99 \%$; negative predictivity, $74 \%$; false-negative rate, $80 \%$; and sensitivity, $20 \%$. Accordingly, the authors proposed that these structural alerts should be subjected to formal validation with a view of incorporating them into regulatory guidelines thereafter.

Expert systems such as MultiCASE, PASS, DEREK, OASIS/TIMES and Tox-
Scope aim to predict the mutagenicity of compounds and/or their major metabolites (Combes et al., 2007). Some systems aim to predict carcinogenicity or other toxic endpoints. For example, the EPA has developed an expert system for the prediction of the carcinogenicity of fibres, metals, polymers, and more than 48 classes of organic chemicals (EPA, 2007), which is freely available at http://www.epa.gov/ oppt/newchems/tools/oncologic.htm. In comparison to conventional rodent bioassays, such computerised systems are rapid and inexpensive.

\subsection{Minimally-sentient organisms}

The use of minimally-sentient animals from lower phylogenetic orders, or early developmental vertebral stages, as well as microorganisms, higher plants, and nonliving physical and chemical systems, can increase compliance with animal use legislation - which frequently regulates only live vertebrate use.

Cosson (2007), for example, proposed the development of protozoal - rather than rodent - assays for bacterial infection, based on the fact that pathogenic bacteria such as Pseudomonas aeruginosa often use the same mechanisms to defend themselves against phagocytosis by unicellular amoebae, and to infect mammalian cells.

The UK Animals (Scientific Procedures) Act (1986; Anon, 1986), for example, allows unregulated use prior to half-way through gestation (in the case of mammals), or incubation (birds and reptiles), or the stage when independent feeding occurs (amphibians and fish). For example, early chicken embryos may be used in reproductive toxicity tests without restriction, and parasites may be similarly cultivated in chicken eggs, for use in parasitological studies (Balls, 1994; Eckert, 1997).

Such strategies may also minimise ethical concerns - although not necessarily to the extent apparent on first examination. For example, there is no clear demarcation between the sentience (and consequent ability to suffer in experiments) of some lower vertebrates, such as certain fish species, and some higher invertebrates, such as certain cephalopod molluscs. Similarly, the stage of development at which animals pass from a legislatively unprotected to a protected state (at least, within the UK), is rarely based on strong scientific justification. Such examples demonstrate the necessity of making decisions appropriate to each case based on both the best available scientific evidence, and also a precautionary principle, mandating that where reasonable doubt exists about sentience, animals should be accorded the benefit of that doubt (Balls, 1994).

\subsection{Tissue cultures}

Tissue cultures are in vitro cultivations of cells, tissues, organs or embryos. Primary cell cultures are isolated directly from animal tissues, often using proteolytic enzymes. Their major advantages include tissue-specific functions and retention of capacity for biotransformation. However, cellular isolation can result in damage to cell membrane integrity, with loss of, or damage to, membrane receptors and cellular products. Fortunately, during the interval necessary to establish monolayer cultures from cell suspensions, such cell damage is often repaired (Broadhead and Bottrill, 1997).

Due to the adverse changes that occur within primary cultures maintained for prolonged periods, it may be necessary to isolate new cells for each experiment. Cell lines eliminate this need. However, extended periods of culture over many years can result in decreased metabolic capacity and altered cellular function. Widely used animal-derived cell lines, such as Chinese hamster ovary cells and mouse lymphoma L5178Y cells, suffer from variation in phenotype and behaviour between laboratories, even with respect to chromosome numbers (Broadhead and Bottrill, 1997).

Immortalised cell lines are capable of extended, and often indefinite, growth in vitro. They are generated by introducing viral oncogenes such as SV40 large $\mathrm{T}$, polyoma virus large $\mathrm{T}$ and adenovirus EIA, into primary cells, using calcium phosphate or electroporation treatment. Examples of cells that have been immortalised include rabbit kidney cells, mouse macrophages, rat hepatocytes, and human lymphocytes and osteoblasts (Broadhead and Bottrill, 1997). Immortalisation of cell lines, however, may significantly al- 
ter their characteristics and function (Luttun and Verfaillie, 2006).

Stem cell lines can be established from mammalian blastocysts (embryonic stem cells (ESCs); Huggins, 2003), or from adult progenitor cells (multipotent adult progenitor cells; Luttun and Verfaillie, 2006). SCs can be maintained in an undifferentiated state in the presence of feeder layers and/or purified leukaemia inhibitory factor (LIF) (Brown et al., 1995). Upon removal of the LIF, SCs differentiate into a variety of cell types (Brown et al., 1995), making them 'pluripotent' in the case of ESCs, or 'multipotent' when isolated from adult organs.

The differentiation potential of adult stem cells was long believed to be limited, although recent evidence has challenged this concept. However, SCs derived from human embryos (hESCs) raise considerable ethical and sociological concerns. The broader the differentiation potential, the more applications can be considered for each stem cell type. As with immortalised cell lines, the self-renewal capacity and potentially unlimited availability also make SCs particularly attractive as a research tool (Luttun and Verfaillie, 2006).

Much of the considerable interest in $\mathrm{SC}$ research centres on their potential to replace lost tissue or functional cells, for example, in degenerative diseases (Luttun and Verfaillie, 2006). In a related application, SC research has helped to elucidate some of the proliferation and differentiation mechanisms involved in haematopoiesis (blood cell production) and, particularly, several haematopoietic cytokines (controlling proteins), which are now used in the treatment of cancer patients undergoing chemotherapy and radiation therapy - which frequently suppresses haematopoiesis (Luttun and Verfaillie, 2006).

Organ cultures are three-dimensional and retain some or all of the histological features of the in vivo equivalent. They may be derived from differentiated SCs. Complex organotypic culture systems, with cofactors and metabolic supplements added, may be used to increase longevity and maintain cellular differentiation (Broadhead and Bottrill, 1997).

One important potential application is the creation of artificial liver constructs for biotransformation studies and drug toxicity testing (Luttun and Verfaillie, 2006). One of the functionally important structural elements of the liver is the sinusoid, which is comprised of a fenestrated vascular structure decorated with hepatocytes. In the adult liver, sinusoids are radially aligned, running from the lobule periphery to the central vein. Odde and Renn (2000) recently developed "laserguided direct writing" (LGDW), enabling the positioning of multiple cell types onto biological matrices with micrometer precision. Cell viability was not significantly impaired (Nahmias et al., 2004). These results suggest that LGDW might be used to create a vascular backbone for ex vivo liver morphogenesis. LGDW could also be used to distribute beads coated with different growth factors onto stem cells, in order to induce their differentiation in a specific spatial pattern (Luttun and Verfaillie, 2006).

Cultures of tissue explants, such as liver slices, may also be used. Their advantages include speed and ease of preparation, the presence of multiple, differentiated cell types, and the maintenance of cellcell and cell-matrix interactions. However, maintenance of viability is difficult, and their use was originally described by Russell and Burch (1959) as relative replacement, because animals are killed to provide cells, tissues and/or organs, and distinct from the ideal of absolute replacement, in which sentient non-human animals are not used at all (Broadhead and Bottrill, 1997).

Tissue cultures can play a valuable role in a variety of interesting toxicological investigations. For example, a number of complementary DNA segments (from which the non-coding intron sequences of the original DNA have been excised; $\mathrm{cD}$ NA) coding for human cP450 enzymes have been cloned, incorporated into eukaryotic expression vectors, and introduced into cell lines, which are then used to study the metabolic capacity of individual cP450 enzymes. Such information may then facilitate identification of compounds that become toxic after biotransformation by these enzymes (Broadhead and Bottrill, 1997).

Similarly, cell lines generated to carry recombinant shuttle vectors can be used to study eukaryotic mutation, because the vectors can be exposed to mutagenic agents in mammalian cells and then transferred to bacteria for rapid analysis of the mutations. Such cell lines can be used for short-term in vitro mutagenesis studies, DNA repair studies, and for studies of the effects of oncogenes, mutator genes and tumour suppressor genes, on mutant frequencies (Broadhead and Bottrill, 1997).

\subsection{In vitro assays}

In vitro assays utilising bacterial, yeast, protozoan, mammalian or human cell cultures exist for a wide range of toxic and other endpoints, including skin corrosion/ irritation, phototoxicity, eye corrosion/ irritation, skin absorption, skin sensitisation, carcinogenicity and systemic toxicity (Huggins, 2003; Murthy, 2007). In vitro assays are not without their limitations (Hartung, 2007). Nevertheless, some have been scientifically validated (demonstrated to be reliable and relevant for the intended purpose; Balls et al., 1990), whilst many others remain under rapid development (Huggins, 2003). A definitive review of the sizeable and speedily evolving field of in vitro assays is well beyond the scope of this review; however, examination of selected assays serves to illustrate their broad potential.

\subsubsection{Perfused cultures}

Tissue cultures may be static or perfused with culture media via pumps. When exposed to toxins, perfusion cultures may allow continuous real-time monitoring of cytotoxicity, through detection and measurement of biomarkers in the perfusion outflow. This can yield important information about onset time, duration and scale of toxicity, which are more difficult to obtain from static cultures or in vivo assays, unless highly specific organic biomarkers indicative of tissue damage are detectable in bodily fluids, such as blood or urine. However, the increased complexity of perfused cultures may limit their use to low-throughput analysis (Jennings et al., 2004).

\subsubsection{Carcinogenicity assays}

In vitro genotoxicity assays are based on the detection of mutagenicity in bacteria or chromosomal damage in mammalian cells. Bacterial mutagenicity assays utilise tester/indicator strains which are hypermutable due to defective cell enve- 
lopes (which enhance the uptake of test chemicals), or deficiencies in DNA repair mechanisms. Different strains may be used to detect chemicals that induce mutagenesis through different mechanisms (Combes et al., 2007).

Mammalian genotoxicity assays often use primary cell isolates, usually of human origin (e.g. lymphocytes), or permanent cell lines, often derived from Chinese hamsters (e.g. ovary or lung) (Mitchell and Combes, 1997). DNA lesions induced following test chemical exposure may include structural aberrations (such as chromosome gaps and breaks induced by clastogens), micronuclei (intracellular supernumary chromatin), or sister chromatid exchanges, as well as numerical abnormalities (e.g. polyploidy and hypodiploidy/hyperdiploidy), indicative of aneuploidy (the state of having a chromosome number that is not an exact multiple of the haploid number) (Parry and Parry, 1995; ECETOC, 1997). Such chromosomal abnormalities are detected following cell replication, using a variety of staining methods or other visual aids (ECETOC, 1997).

Such genotoxicity assays may play an important role in carcinogenicity testing. Brusick (1977), for example, found a correlation of approximately $90 \%$ between in vitro microbial mutagenesis and mammalian carcinogenic endpoints for a large array of chemicals. Tennant and colleagues (1990) successfully predicted the outcomes of $86 \%$ of 44 chemicals undergoing carcinogenicity testing by the NTP, by using the Salmonella mutagenicity and sub-acute (90-day) rodent toxicity tests, in combination with chemical structural information. The Ames Salmonella typhimurium reverse mutation and chromosomal aberration (CA) genotoxicity assays have been accepted by regulatory agencies for many years (Dearfield et al., 1991).

Cell transformation assays (CTAs) detect morphological changes that provide the earliest phenotypically identifiable signs of carcinogenicity. In fact, these assays provide the main non-animal methods for modelling carcinogenicity, and were comprehensively reviewed by Combes and colleagues (1999, 2007). CTAs may be used to detect both genotoxic and non-genotoxic carcinogens (GCs and NGCs).
CTAs have been devised using rodent cell lines (e.g. Balb/c 3T3 cells; Tsuchiya and Umeda, 1995, Tsuchiya et al., 1999), and immortalised fibroblast cell lines of rodent or human origin (e.g. C3H10T1/2 cells; Reznikoff et al., 1973; Landolph, 1985). The Syrian hamster embryo (SHE) cell transformation assay has been described as the most predictive short-term assay for rodent carcinogens (Zhang et al., 2004). Pienta and colleagues (1977) showed a $91 \%$ correlation between the morphological transformation of SHE cells - despite their prior cryopreservation - and the reported carcinogenic activity of numerous carcinogenic and non-carcinogenic chemicals. The particular advantage of the SHE assay in comparison to many other in vitro assays is its high sensitivity for NGCs, as well as GCs (Amacher and Zelljadt, 1983; Mauthe et al., 2001).

Whilst GCs often exert their effects across a range of species, sexes and target organs, the detection of NGCs may be particularly challenging, because of the wide diversity of their potential modes of action, which are often species-, sex- and tissue-specific. Some exert their effects after binding to specific cellular receptors, whilst others involve epigenetic changes coupled with cellular proliferation. Some mechanistically-based assays are being developed and used specifically for the detection of such NGCs. Examples include: assays designed to detect ligand binding to nuclear and cell membrane receptors, e.g. Ah receptor binding; in vitro reporter gene assays to detect binding resulting in up-regulation of receptors or transcriptional activation; in vitro cell proliferation assays, e.g. the serum-free liver mitogen test; the in vitro gap junction intercellular communication (GJIC) assay, designed to detect the inhibition of GJIC believed to result from exposure to some NGCs; and the in vitro detection of angiogenesis, to assess the ability of the test substance to elicit the later stages of tumourigenesis (Combes, 2000; Combes et al., 2007).

\subsubsection{Test batteries}

Batteries of in vitro assays may be used to increase the spectrum of toxins detected (applicability domain). Kirkland and colleagues (2005) examined the ability of a battery of three of the most commonly used in vitro genotoxicity assays: the Ames Salmonella typhimurium, the mouse lymphoma assay, and the in vitro micronucleus or CA tests, to correctly predict the rodent carcinogenicity of 700 known chemicals. While the sensitivity of the battery was high $(93 \%$ of chemicals with reliable genotoxicity data yielded positive results in at least one test), the specificity was variable. The low specificity of the mammalian cell assays declined further when combined as a battery. However, by adopting relative predictivity (RP) ratios of true:false results, it was established that positive results in all three tests indicated that rodent carcinogenicity was more than three times likelier than non-carcinogenity, and also that negative results in all three tests indicated that rodent non-carcinogenicity was more than twice as likely as carcinogenicity. Accordingly, the authors recommended the use of RP ratios to assess the likelihood of carcinogenicity or non-carcinogenicity, for chemicals with batteries of positive or negative results.

\subsubsection{GreenScreen genotoxicity assays}

Lichtenberg-Frate and colleagues (2003) demonstrated the genotoxic and cytotoxic sensitivities of a genetically modified yeast (Saccharomyces cerevisiae) assay that used a yeast-optimised version of green fluorescent protein fused to the RAD54 yeast promoter, which is activated upon DNA damage. The result was green fluorescence in the presence of several genotoxic test compounds. This elegant assay was thereafter known as a GreenScreen

A similar assay appeared to detect a number of genotoxins and non-genotoxins with a very high level of accuracy, in a study of some 75 chemicals (Hastwell et al., 2006).

Akyüz and Wiesmüller (2003) also described a GreenScreen assay for the detection of genotoxicity, but in this case living human cell cultures were studied. The assay detected the genotoxic effects of ionising radiation, of a compound that tested positive in a traditional Ames bacterial mutagenicity assay, and also, of two compounds that were poorly mutagenic in the Ames assay. 
As Cahill and colleagues (2004) observed, the spectrum of compounds detected by the GreenScreen is somewhat different to that detected by bacterial genotoxicity assays, and hence this assay, when combined with a high-throughput bacterial screen and an in silico SAR screen, might provide an effective battery of genotoxicity screening tests for regulatory purposes.

Additional advantages include the possibility of assessing the impact of human metabolites, for example, by the addition of liver extracts, or by using transgenic cell lines with human metabolising enzymes. The potential for automated performance and flow cytometric analysis also make the human-based assay described by Akyüz and Wiesmüller amenable to high-throughput.

\subsubsection{Human hepatocyte assays} Human hepatocyte assays play a key role in pharmaceutical development. The liver usually receives the highest bolus concentration of an ingested drug, delivered from the intestines via the portal circulation. Furthermore, hepatocytes produce P450-dependent monooxygenases, and hence, are the major cells responsible for drug metabolism, and the first cells to be affected by any reactive or toxic metabolites produced. Accordingly, human hepatocyte cultures are the in vitro system of choice when studying human drug-induced processes (Ullrich et al., 2007; Li, 2008a). They are now routinely used for metabolic profiling (identification of metabolites formed from the parent drug), and the assessment of drug-drug interaction potential and toxicity, in both academic and industrial laboratories. Standardised and validated human hepatocyte culture systems now exist (e.g. Ullrich et al., 2007). The development of cryopreservation using protocols and reagents designed to protect membranes from damage associated with cryopreservation and subsequent thawing, and the development of protocols and media allowing cultivation of differentiated, functional human hepatocytes, have all facilitated their widespread use (Ullrich et al., 2007; Li, 2005, 2008a).

\subsubsection{Assesment of metabolite activity and organ- organ interaction}

The inability of most cell cultures to mimic organ-organ interactions occurring in vivo represents an important limitation of isolated organ cultures. The importance of considering multiple organ interactions is illustrated by the potential generation of toxic metabolites by the liver, which may exert effects in distal organs (Li, 2008b). Although such reactive metabolites are believed to constitute a significant proportion of all toxins, for most compounds the degree of toxicity resulting from metabolic activation is unknown (Langsch and Nau, 2006).

Hence, models such as the Integrated Discrete Multiple Organ Co-culture (IdMOC) system developed by $\mathrm{Li}$ and colleagues (2008b) are particularly significant. Developed for the evaluation of xenobiotic toxicity, the IdMOC system utilises a wells-in-a-well structure. Cells from different organs are co-cultured in discrete inner wells, but interconnected by an overlying medium integrated into the outer well. The system models multiorgan human or animal in vivo systems, in which organs are physically separated yet interconnected via the systemic circulation. Physical separation of different cell types facilitates evaluation of organspecific effects, which is extremely difficult when using mixed-cell type cocultures.

Potential applications of the IdMOC system include the evaluation of multiple-organ metabolism, as well as organspecific drug distribution and toxicity. Maximal human relevance is achieved through the use of human xenobiotic metabolising cells, such as hepatocytes, and human target organ cultures. A particularly interesting application is the co-culturing of cancer cells and cells representing major organs, for the selection of anticancer agents with minimal organ toxicity (Li, 2008b).

Given that pathways of metabolic activation are frequently uncertain - particularly during high-throughput screening, such metabolic activation systems should ideally include all possible relevant hepatic or other enzymes (Langsch and Nau, 2006). Such preparations may also be used to identify metabolic pathways and enzyme systems involved in biotransformation, and active metabolites produced.

\subsubsection{Quality control of biologicals}

Regulatory safety and potency testing for biological materials, such as vaccine batches, has traditionally relied on animal models. Indeed, the quality assurance and production of medicines accounts for around $15 \%$ of all regulated EU scientific animal use (Leist et al., 2008a). Such tests are responsible for a high proportion of experiments resulting in severe, unrelieved pain and suffering (Stephens et al., 2002). However, the consistency approach has facilitated reductions in such animal use within the field of vaccine testing. Each vaccine batch is recognised as one of a series produced from the same starting material (seed lot), which shares many common characteristics with other batches, rather than as a unique product. This allows for a quality control strategy focusing on production consistency, achieved through compliance with Good Manufacturing Practice and Quality Assurance principles, and assessment at various stages during the production process using non-animal test models, such as physicochemical methods and in vitro assays. Examples of recent achievements in the quality control of toxoid vaccines include the replacement of challenge procedures by serological methods, and reductions in animal numbers achieved by changing from multi- to single-dose testing (Hendriksen, 2006).

Pyrogens (fever-inducing contaminants) can be a major health hazard in parenteral drugs, when cytokines such as interleukin- $1 \beta$, interleukin-6 or tumour necrosis factor- $\alpha$ are produced. These cytokines may produce acute adverse reactions that can range from induction of fever to life-threatening pyrogenic shock with multi-organ failure (as occurred in the case of TGN1412 - see following), depending on the concentration of the stimulus and its intrinsic activity (Montag et al., 2007). Hence, pyrogen testing may be required prior to batch release (e.g. the European Pharmacopoeia made such testing of small volume parenterals obligatory in 2004). This was traditionally 
achieved by the in vivo rabbit pyrogen test (since 1942) or the limulus (horseshoe crab) amoebocyte lysate test (LAL, since 1976).

However, six variants of human immune cell-based assays have been validated in a collaborative international study. Such human in vitro assays can achieve sensitivities and specificities of greater than $90 \%$ for human pyrogens, and - in contrast to the LAL - may detect nonendotoxic pyrogens derived from Grampositive bacteria or fungi (Schindler et al., 2006a,b). Sensitivity and consistency may also exceed that of rabbit assays (Schindler et al., 2007). They may also provide insights into mechanisms of pyrogenicity and acute pro-inflammatory reactions in patients (Montag et al., 2007).

\subsubsection{Drug hypersensitivity prediction}

Drug hypersensitivity reactions are known to be mediated by covalent binding of drug haptens (partial antigens) to proteins, which are processed to peptides and presented on MHC-structures (major histocompatability complexes, comprised partly of human leukocyte antigen). These hapten-peptide complexes are recognised by $\mathrm{T}$ cells with receptors (TCRs) that fit the antigen in question (Pichler, 2007).

However, using blood mononuclear cells, Pichler (2007) showed that direct non-covalent binding of drugs to TCRs is also possible, and may also stimulate $\mathrm{T}$ cells into dividing and triggering inflammatory responses through cytokine secretion, resulting in cell death (p-i concept- direct pharmacological interaction of drugs with immune receptors).

Such immune-mediated inflammatory responses may cause mild symptoms, such as maculopapular exanthema, through to severe reactions, such as Stevens-Johnson Syndrome, toxic epidermal necrolysis, hepatitis, pancreatitis, fever, vasculitis, eosinophilia, and even death (Pichler, 2007).

For testing the safety of systematically (orally or parentally) applied drugs that act via this p-i mechanism, human-based in vitro assays are necessary, because such immunological reactions are highly species-specific. Small alterations of TCR morphology may dramatically alter $\mathrm{T}$ cell reactivity. Furthermore, reactivity varies even between human individuals, both in vivo and in vitro, for reasons that are hypothesised to include variations in TCR repertoires, immune regulation and genetic background. Pichler speculated that a greater understanding of these factors could lead to novel human-based in vitro assays for drug hypersensitivity.

\subsubsection{Bone-seeking pharmaceuticals}

Treatment and monitoring of osseous tumours requires bone-seeking pharmaceuticals, such as radioactively labelled polyphosphonates (MDP, DPD, EDTMP, etc.). Despite their use for over 30 years, however, uncertainty about the binding interaction between bone-seeking pharmaceuticals and target bone impedes rational drug design of novel bone seekers, such as analysis of SARs. Accordingly, biodistribution and efficacy studies in laboratory animals have traditionally been utilised early in preclinical evaluation (Mitterhauser and Toegel, 2008).

Mitterhauser and Toegel, however, described an in vitro assay based on simple binding to hydroxyapatite $\left(\mathrm{Ca}_{5}\left(\mathrm{PO}_{4}\right)_{3} \mathrm{OH}\right.$ - a mineral phosphate of calcium that is the principal structural element of vertebrate bone). In vitro binding characteristics correlated well with those obtained in vivo using mice, and ex vivo using human donor bone. Accordingly, this assay provides a viable alternative to animal models for the comparative evaluation of novel bone seekers.

\subsubsection{Developmental toxicity assessment using embryonic stem cells}

Organisation for Economic Cooperation and Development (OECD) Test Guidelines for the assessment of developmental toxicities such as embryotoxicity and teratogenicity are costly and time consuming. Two- or multigeneration studies may consume up to 3,200 animals per substance (OECD Test Guideline 414: Prenatal Developmental Toxicity Study), and it is expected that developmental toxicity testing will consume the highest animal numbers within REACH (Pellizzer et al., 2005).

The use and further development of appropriate in vitro systems is therefore a high priority. These may include cell cultures (e.g. embryonic stem cell tests (ESTs)), organ cultures (e.g. micromass assays), and embryo cultures (e.g. whole embryo cultures) (Huggins, 2003; Pellizzer et al., 2005). Brown (1987), and Brown and colleagues (1995), provided extensive overviews of existing in vitro systems. The ability of ESCs to differentiate into a wide range of potentially vulnerable target tissues maximises their utility. They may be used to test for embryo toxicity in vitro, and to screen for teratogenicity and growth retardation (Luttun and Verfaillie, 2006). hESCs are preferable, as resultant assays are relatively simple and reproducible, avoid interspecies differences, and may facilitate study of human development.

Several approaches are possible using ESCs. Traditionally, toxicity has been assessed by morphological analysis of toxic inhibition of beating cardiomyocytes in embryoid body outgrowths derived from murine ESCs (Luttun and Verfaillie, 2006), although the objectivity of this assay has been criticised (Buesen et al., 2004). An immunological assay was described by Seiler and colleagues (2002 and 2004), which utilised intracellular staining and flow cytometry to detect changes in sarcomeric myosin heavy chain and alpha-actinin during cardiac differentiation of ESCs. Cultivation of transgenic ESCs with green fluorescence protein, driven by a specific tissue gene promoter, may allows visual detection of teratogenicity (Metzger et al., 1996; Kolossov et al., 1998; Bremer et al., 2001; Paparella et al., 2002). Array technologies (see following) now allow detection of changes in the expression of thousands of genes simultaneously (Lockhart and Winzeler, 2000), following chemical exposure. Analysis of gene expression profiles at different stages of cardiac and skeletal ESC differentiation has been used to identify developmental stages of chemical vulnerability (Pellizzer et al., 2004a,b).

An international ECVAM study validated the EST using a set of 20 reference compounds characterised by highquality in vivo embryotoxicity data from laboratory animals and humans. The EST predicted the embryotoxicity of the 20 compounds with $78 \%$ accuracy, and $100 \%$ predictivity was obtained for 
strong embryotoxins (Genschow et al., 2002, 2004). Similarly, Whitlow and colleagues (2007) recently conducted ESTs on six chemicals with toxicity characteristics established from literature and this ECVAM study, and on 10 Roche internal pharmaceutical substances already tested in vivo. Their EST model correctly classified $81 \%$ of substances.

Clearly, ESCs offer several avenues for the identification and investigation of teratogenicity, in a wide range of differentiated tissues, although ESTs only detect embryotoxicity occurring early in embryogenesis. However, detection of compounds that show such toxicity is a high priority (Buesen et al., 2004). In recognition of this, and of their potential during embryotoxicity testing, investigation of hESCs is included within an important integrated project entitled ReProTect, which is part of the 2002 EU $6^{\text {th }}$ Research Framework Programme. The ReProTect collaboration includes 35 academic, governmental and other institutions, and was allocated $€ 9.1$ million over 5 years. Its principal aim is to create new in vitro models, and combine these with existing models within a test strategy aimed at providing information on chemical hazards to the mammalian reproductive cycle (Pellizzer et al., 2005).

Considerable standardisation and harmonisation of hESC assays remains necessary, however, along with enlargement of the reference database and consolidation of the details of the existing prediction model, to ensure their regulatory acceptance. The introduction of a metabolic system as an adjunct to the validated EST protocol - which is only applicable for compounds that do not need metabolic activation - will also be necessary (Buesen et al., 2004).

Varying international approaches to embryo protection and other ethical issues raised by hESC research also present significant obstacles (Pellizzer et al., 2005). Among other restrictions within the relevant 2003 EC guidelines, for example, is the statement that, "Research will be funded only when there is no adequate alternative available. In particular, it must be demonstrated that one cannot use existing embryonic or adult stem cell lines" (EC, 2003).

\subsubsection{Brain tissue cultures}

Bacterial meningitis has an in-hospital mortality of approximately $25 \%$, and up to $50 \%$ of survivors suffer neurological sequelae secondary to brain damage. Evidence suggests that lesions result primarily from host immune responses. To date, the pathogenesis of brain infections, and the efficacy of potential therapeutic approaches supporting brain repair, have been largely investigated in animal models, many of which experience suffering graded as intermediate to severe. In vivo models have been considered necessary, because of the complexity of the pathogenesis of meningitis, which involves interactions between the host's inflammatory system, susceptible brain cells and the bacterial pathogen itself (Leib, 2007).

Leib (2007), however, described the development of an in vitro model aimed at reproducing important pathophysiological processes of damage and tissue regeneration, in infectious brain diseases. Objectives include differentiating neuronal stem cells into defined developmental stages susceptible to injury, and subsequently challenging them with infectious pathogens, and/or inflammatory mediators; and also, to evaluate the integrative and therapeutic potential of neuronal precursors or stem cells, as transplants into brain tissue. Leib and colleagues have developed an organotypic cell culture system capable of facilitating the culturing of hippocampal or cortical brain tissue, whilst maintaining key elements of natural architecture, and natural distribution of cell types. Brain injury secondary to bacterial meningitis prominently affects the cortex and hippocampus.

\subsubsection{Genetic engineering}

Incorporation of green fluorescent protein into cells to provide visual confirmation of genetic damage has been previously described. Another particularly important application of genetic engineering is the incorporation of endogenous xenobiotic metabolising enzymatic ability within established cell lines. This can confer the ability to screen for toxicity and provide information about molecular mechanisms of metabolism.

Xenobiotic metabolising enzymes have now been expressed in bacteria, yeast, insect and mammalian cells. Over 20 cell lines, mostly derived from human and hamster tissues, have been genetically engineered for the expression of xenobiotic metabolising enzymes, within the last decade. Much of this development has relied on recombinant DNA techniques (Weibel et al., 1997). cDNA encoding for nearly every major human P450 isoform has been isolated and sequenced (Crespi, 1995).

Recent research has focused on the isolation of the activity of single enzymes within a metabolic profile, followed by study of the activities of multiple enzymes acting in sequence, as occurs in vivo. Despite considerable progress in this field, concerns remain about in vivo applicability, and much validatory work remains necessary (Huggins, 2003).

\subsection{Toxicogenomics}

Toxicogenomics is the application of genomics (the study of genomes), to toxicology. Related fields include transcriptomics, proteomics and metabolomics. Toxicogenomics seeks to link induced gene expression changes with classes of toxic compounds (Farr and Dunn, 1999; Aardema and MacGregor, 2002). For example, Ellinger-Ziegelbauer and colleagues (2008) identified gene expression profiles characteristic of GCs and NGCs based on liver samples from rats treated for up to 14 days. Based on these results, they were able to predict the carcinogenicity profiles of an independent set of validation compounds with up to $88 \%$ accuracy.

cDNA microarrays (gene chips) contain hundreds or thousands of microscopic spots of cDNA transcripts of mRNA templates. They offer the ability to examine many genes simultaneously, and to characterise phenotypic changes in whole cells or organs. This may considerably speed up the generation of results, in comparison to less modern methods, such as the analysis of mutation frequency by phenotypic selection, analysis of transcription (mRNA) by Northern blotting, or analysis of translation (proteins) by Western blotting. Furthermore, with durations of days rather than years, and with the ability to detect toxic changes well prior to traditional, more invasive endpoints, cDNA microarrays may facili- 
tate considerable refinement of laboratory animal use (Knight et al., 2006a).

Particularly exciting is the ability of cDNA microarrays to detect NGCs (Goodman, 2001). After exposing rat hepatocytes to several rodent GCs and NGCs, as well as to two non-carcinogenic hepatotoxicants, during five day, repeat-dose in vivo studies, Kramer and colleagues (2004) hybridised fluorescently-labelled probes generated from liver mRNA against rat cDNA microarrays. Correlation of the resulting data with the estimated carcinogenic potential of each compound and the dose level identified several candidate molecular markers of rodent non-genotoxic carcinogenicity, including transforming growth factor- $\beta$ stimulated clone 22 and NAD(P)H cP450 oxidoreductase.

However, microarray technology remains very new, and a number of existing limitations would benefit from further research and development (Knight et al., 2006a). It is expected that many of the genes affected by toxicant action will be identified within the next twenty years, leading to progressively greater utility of gene chips as replacements for animal use within toxicity testing (Huggins, 2003).

\subsection{Other human studies}

\subsubsection{Clinical trials}

Clinical studies in human volunteers are an essential component of drug development. They seek to identify differences between the effects of pharmaceuticals in preclinical studies, and humans, and to evaluate their human safety and efficacy.

In 2006, however, during a UK Phase 1 (first-in-humans) trial on the anti-inflammatory monoclonal antibody TGN1412, all six volunteers rapidly developed cytokine release syndrome after dosing, culminating in multiple organ failure, requiring intensive care. One volunteer suffered permanent damage. These severe adverse reactions occurred despite thorough preclinical trials, which had included computer modelling, and tests on human cells, mice, rats, New Zealand White rabbits, marmosets, rhesus macaques and cynomolgus monkeys, and despite subsequent authorisation by the Medicines and Healthcare Products Regulatory Agency, and the relevant institutional Medical
Ethics Committee. They occurred despite correct drug manufacturing processes and administration in accordance with approved protocols (Northwick Park Hospital, 2006; MHRA, 2006; Bhogal and Combes, 2006).

Such cases highlight the lack of certainty of existing preclinical studies when predicting human risks, and the necessity of compliance with measures designed to minimise those risks. Such measures were discussed in detail by Bhogal and Combes (2006), and at a recent NIH meeting (Kramer et al., 2006). They include:

1. Releasing the outcomes of pre-clinical and clinical studies into the public domain, either once the drug is marketed or when it has been deemed to fail. Such data may guide further research and development, and may influence the design of future clinical trials. Such safety and efficacy-based considerations must be correctly acknowledged as superseding concerns about commercial confidentiality.

2. Greater effort should be invested into the development and use of preclinical test methods more predictive for human outcomes, particularly the use of human cells and tissues in culture, and especially in areas presently poorly modelled, such as the immune system (Silliman and Wang, 2006). Data from such tests should be considered at least as important as traditional animal test data.

3. The first administration to humans should utilise microdoses (Phase 0 studies). The role of microdoses in early drug development was recently reviewed by the FDA (CDER, 2006). Microdose studies generally seek to provide information on human pharmacokinetics and bioavailability (Combes et al., 2003), rather than pharmacological effects. They use doses less than $1 / 100^{\text {th }}$ of pharmacologically active doses, as estimated from preclinical studies. However, they may not exhibit threshold or other dose-dependent effects.

4. Increased research should be conducted with the goal of identifying biomarkers of toxicity, such as the presence of metabolite activating and detoxifying enzymes (Besaratinia et al., 2002), cellular markers of exposure, the pres- ence of mutagens in body fluids, and chromosomal alterations (Cone and Rosenberg, 1990). Volunteers should be carefully monitored for the expression of such biomarkers following microdosing, with assessed biological parameters expanded to incorporate possible macroscopic effects, as doses are increased.

5. Dosing should be staggered, rather than concurrent, perhaps based on expected in vivo half-lives. In the case of TGN1412, adverse clinical signs were evident within two hours of dosing; hence staggering doses by as little as one hour would have significantly reduced the number of volunteers affected.

6. The limited predictivity for broader populations of human clinical trials may result from their focus on small groups of healthy young men, or from insufficient study durations. Particularly in Phases I-II, small cohorts of young men (20-300) are typically used to minimise experimental variability, and to eliminate possible endocrinological disruption or other risks to women of reproductive age. Although 1,000-3,000 volunteers may be used in Phase III trials - the final phase before marketing (NIH, 2006) - it is nevertheless clear that cohort numbers, study durations or other aspects of protocol design, conduct or interpretation are inadequate to detect the adverse side effects of the large number of pharmaceuticals that harm patients after marketing. Longer studies of more broadly representative human populations would be more predictive.

7. When drugs are specifically targeted to modulate systemic processes, such as immune system activity, serious consideration should be given to using appropriate patients, rather than healthy volunteers, as soon as physiologically active doses are reached. Immunocompromised patients, for example, might not display the adverse reactions elicited in healthy, immunocompetent volunteers.

Such strategies would probably increase the already substantial time and cost of pharmaceutical development. However, with adverse reactions to pharmaceuticals comprising the $4-6^{\text {th }}$ leading 
cause of death in US hospitals (based on a 95\% confidence interval; Lazarou and Pomeranz, 1998), it is clearly necessary to question the safety for human patients of the traditional drug testing paradigm.

\subsubsection{Epidemiological, sociological and psychological research}

Despite our extensive tradition of animal testing, little certainty exists about the human toxicity of the vast majority of chemicals in widespread use. Increased epidemiological research (the identification of aetiological agents or risk factors through population studies), would enable definitive identification of more human toxins. This would also increase the data set available for validation studies of test models. Concurrent human sociological or psychological studies may increase our understanding of factors predisposing toward risky lifestyle choices.

In some cases, existing social infrastructure can be recruited in support of such studies. For example, cancer treatment centres could be funded to establish tumour registries aimed at identifying new lifestyle, occupational, environmental and medical carcinogens. Post-marketing surveillance of human pharmaceuticals, with reporting of adverse side effects, is already required in most jurisdictions, and should be fully utilised, perhaps through provision of incentives to participating physicians, whose available time may be very limited.

\subsubsection{Additional human investigation}

A wide range of other investigative tools is available for the non-invasive examination of human beings. To varying degrees, biomechanical and other bodily systems and processes may be modelled mathematically, and their behaviour predicted by computerised simulations (Langley et al., 2007). For example, the effects of dental or surgical interventions may be simulated by incorporation of the biomechanical characteristics of various human tissues within mathematical models. The structural properties of human tooth, bone and ligament, and of dental materials such as ceramic and titanium, can be incorporated into simulations of dental prosthetic implants, allowing predictions of stresses and strains, and of the effects on implant movement and fracture probabilities of various mechanical or thermal loads (Gallas et al., 2005). Such simulations rely on finite element (FE) analysis - an engineering technique. Structures are modelled by subdividing them into a meshwork of theoretical elements bounded by nodes. The magnitude at various nodes of effects such as strains and stresses applied to the structure can then be computed mathematically. FE analysis has been widely applied in studies of dental materials, oral and maxillofacial surgery, orthodontics and dental restorations (Mackerle, 2004).

The use of donated human tissue or cell lines is appropriate for certain biochemical questions - such as those investigating human cellular receptors. In some cases surrogate tissues may be used. For example, mast cells isolated from human placenta have some features in common with neurons - including the possession of a functional receptor for nerve growth factor, and may therefore be used for appropriate neuropharmacological, neurophysiological and neurotoxicological studies (Purcell and Atterwill, 1995).

As stated, the ability of hESCs to produce a wide range of differentiated cell types makes them particularly valuable. Schrattenholz and Klemm (2007), for example, described models of human neu- rodegenerative diseases based on neurons derived from hESC precursors. Using calcium imaging (because various neuropathological processes appear to be associated with altered calcium levels), mitochondrial potential measurements and Western blots, they demonstrated their functionality, and further, that the model reproduced crucial mechanistic aspects observed during ischaemia and excitotoxicity, that are considered central to some neurodegenerative diseases.

Anatomical investigations of donated human cadavers and tissues may be conducted via gross or histological examination, and a variety of imaging techniques may be used in human volunteer studies, such as plain or contrast radiographs, ultrasonography, computed tomography, functional magnetic resonance imaging (fMRI), and positron emission tomography (PET). Such minimally-invasive investigative tools may also be applied within animal studies, thereby achieving refinement of animal use.

Even the complexities of the human brain may sometimes be amenable to such study. Neural activity in various regions of the brain can be correlated with specific cognitive, physiological or physical activities via fMRI or PET. The functional necessity or redundancy of regions thereby identified can be investigated using transcranial magnetic stimulation.

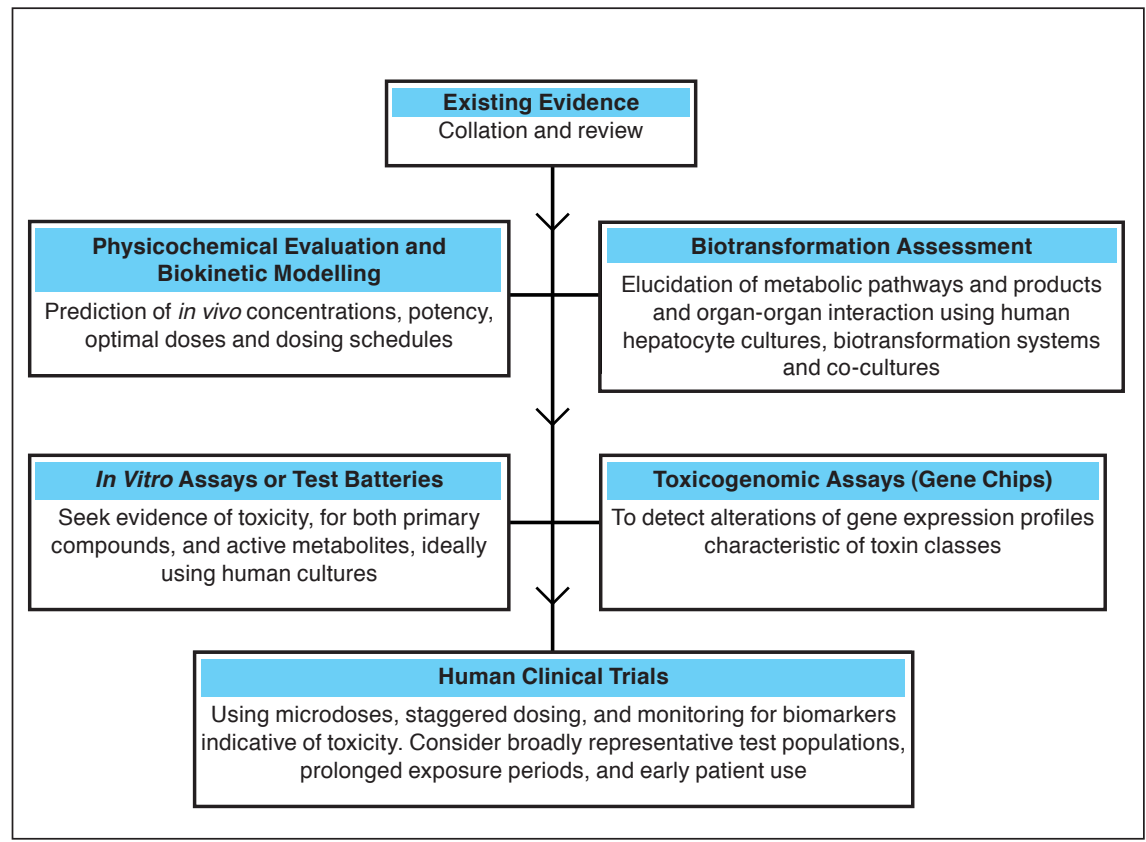

Fig. 1: Integrated toxicity testing 
Applied using a coil, an electromagnetic field disrupts neurological activity in an area of interest for tens of milliseconds or longer, during which period volunteers perform cognitive, visual or other tasks (Barker et al., 1985; Schriefer et al., 1988; Langley et al., 2000; Heindl et al., 2008).

\subsection{Integrated toxicity testing strategies}

Toxicity testing protocols utilising tiered combinations of non-animal assays have been described, for example by the UK Department of Health (2000), Worth and Balls (2002), Knight and colleagues (2006a), Combes (2007), and Combes and colleagues (2007). They should include elements appropriate to the individual case, which would normally be conducted in sequence, as in Figure 1.

Not all testing stages will be necessary in every case, particularly when positive toxicity data are obtained in earlier stages. The appropriate level of testing will be influenced by factors such as production volumes, human exposure risks, and legislative or regulatory requirements.

Not all appropriate assays will have been scientifically validated, nor adopted by regulatory authorities. However, properly collating and examining the more targeted data obtained through such a testing scheme is likely to yield a weight-of-evidence characterisation for human toxicity of superior predictivity to that currently offered by conventional animal-based assays, such as the traditional rodent bioassay. It may also facilitate greater understanding of mechanisms of toxicity.

\section{Conclusions}

A definitive review of non-animal research and testing methodologies would be impossible, in anything less than a series of dedicated volumes. Nevertheless, it remains clearly apparent from this limited review that a broad range of investigative tools exists, with the potential to replace animal use within biomedical research and toxicity testing. These include mechanisms to enhance the sharing and assessment of existing data prior to conducting further studies; physicochemical evaluation and computerised modelling, including the use of SARs and expert systems; and the use of minimally-sentient animals from lower phylogenetic orders, early developmental vertebral stages, microorganisms, and higher plants.

A variety of tissue cultures are available, including immortalised cell lines, embryonic and adult SCs and organotypic cultures. In vitro assays utilising bacterial, yeast, protozoal, mammalian or human cell cultures exist for a wide range of toxic and other endpoints. These may be used individually or combined as batteries, and kept static or perfused. Human hepatocyte cultures and metabolic activation systems may facilitate identification of metabolic pathways, determination of metabolites produced, and assessment of organ-organ interaction. Microarray technology may allow genetic expression profiling of toxins, increasing their speed of detection, well prior to more invasive endpoints.

Enhanced human clinical trials utilising microdosing, as well as surrogate human tissues, advanced imaging modalities and human epidemiological, sociological, and psychological studies, may all increase our understanding of illness aetiology and pathogenesis, and facilitate the development of safe and effective pharmacologic interventions.

Non-animal investigative methods cannot, of course, provide answers to all questions about humans, particularly given present technological limitations. However, the same is certainly true of animal models, which have a more limited capacity for further development.

However, non-animal models can offer certain important advantages, when compared to animal use. Particularly when humans or human tissues are used, such alternatives may generate faster, cheaper results, more reliably predictive for humans, and may yield greater insights into human biochemical processes. Such considerations are becoming increasingly important, given the logistical challenges posed by the high-throughput toxicity testing requirements of US and EU testing programmes such as HPV and REACH, and also, increasing social pressures to find alternatives to laboratory animal use, reflected in legislative or regulatory changes, such as the $7^{\text {th }}$ Amendment to the EU Cosmetics Directive.
However, despite substantial ongoing progress in the development of nonanimal alternatives, compliance with the spirit of the 3Rs and, indeed, the letter of some associated regulations, unfortunately remains poor within some sectors of government, academia and industry. Continued reliance on animal models is understandable when truly required by regulators for the licensing of drugs and chemicals. The position of such regulators themselves appears less justifiable, however. Some apparently "feel more comfortable" with animal data (O'Connor, 1997), or even believe animal tests are inherently valid, simply because they are conducted in animals (Balls, 2004). Yet, such reliance on animal models persists for historical and cultural reasons, rather than because they have been demonstrated to be scientifically valid. Animalbased toxicology, at least, indeed appears to be "frozen in time, using and accepting the same old animal models again and again, often without stringent examination of their validity" (Hartung, 2008a; Leist, 2008b).

In many cases particular alternatives have been developed and successfully used at a particular laboratory, but transfer of such technology elsewhere is minimal. Reproducibility and transfer would be assisted by increased description and standardisation of methodologies. Journal space is limited, and so Gruber and Hartung (2004) proposed the establishment of publicly-accessible methodology databases, which could provide supplementary links to articles - a simple accomplishment, given modern technology.

As Gruber and Hartung observed, however, more fundamental problems appear to exist. These include incorrect assumptions of the human utility of animal models, and a dearth of interest in exploring alternatives to animal use. Greater commitment to the development and use of non-animal alternatives is clearly necessary, to maximise efficiency when meeting the needs of high-throughput toxicity testing programmes, the ongoing development of human clinical interventions, and important emerging testing needs, such as the toxicity testing of nanoparticles, genetically-altered or irradiated food, and mobile phone radiation - none of which can be adequately assessed us- 
ing classical animal models (Leist et al., 2008b).

Several mechanisms could substantially assist this process. Public funds previously spent on animal tests required by regulators could be redirected into the further development and implementation of alternatives (Gruber and Hartung, 2004). Considerably more stringent compliance with relevant animal welfare legislation requiring the consideration or use of alternatives could - and should - become a prerequisite of research funding, ethics committee approval of experiments, and publication of results. These measures would require the education and cooperation of funding agencies, ethics committees and journal editors, about the limitations of animal models, and the potential of non-animal alternatives. Each of these measures is eminently achievable. All that is required is the will to do so.

\section{References}

Aardema, M. and MacGregor, J. T. (2002). Toxicology and genetic toxicology in the new era of "toxicogenomics": impact of "omics" technologies. Mutat. Res. 499, 13-25.

Akyüz, N. and Wiesmüller, L. (2003). Proof of principle: detection of genotoxicity by a fluorescence-based recombination test in mammalian cells. ALTEX 20(2), 77-84.

Amacher, D. E. and Zelljadt, I. (1983). The morphological transformation of Syrian hamster embryo cells by chemicals reportedly nonmutagenic to Salmonella typhimurium. Carcinogenesis 4, 291-295.

Andersen, M. E. (1991). Physiological modelling of organic compounds. Ann. Occup. Hyg. 35, 309-321.

Anon (1986). Animals (Scientific Procedures) Act 1986. London, UK: HMSO.

Ashby, J. and Tennant, R. W. (1991). Definitive relationships among chemical structure, carcinogenicity and mutagenicity for 301 chemicals tested by the U.S. NTP. Mutation Research 257, 229 306. Erratum in Mutation Research 1994, 317, 175.

Balls, M., Blaauboer, B., Brusick, D. et al. (1990). Report and recommendations of the CAAT/ERGATT workshop on the validation of toxicity test procedures.
ATLA 18,313-337.

Balls, M. (1994). Replacement of animal procedures: alternatives in research, education and testing. ATLA 28, 193-211.

Balls, M. (2004). Are animal tests inherently valid? ATLA 32 Suppl. 1B, 755758.

Balls, M. and Combes, R. (2006). Validation via weight-of-evidence approaches. ALTEX 23 Sp. Issue, 332-335.

Barker, A. T., Jalinous, R. and Freeston, I. L. (1985). Non-invasive magnetic stimulation of the human motor cortex. Lancet 1, 1106-1107.

Benigni, R., Passerini, L. and Rodomonte, A. (2003). Structure-activity relationships for the mutagenicity and carcinogenicity of simple and alpha-beta unsaturated aldehydes. Environ. Mol. Mutagen. 42, 136-143.

Besaratinia, A., Kleinjans, J. C. and Van Schooten, F. J. (2002). Biomonitoring of tobacco smoke carcinogenicity by dosimetry of DNA adducts and genotyping and phenotyping of biotransformational enzymes: a review on polycyclic aromatic hydrocarbons. Biomarkers 7, 209-229.

Bhogal, N. and Combes, R. (2006). TGN1412: time to change the paradigm for the testing of new pharmaceuticals. ATLA 34, 225-239.

Blaauboer, B. J., Hermens, J. and van Eijkeren, J. (2006). Estimating acute toxicity based on in vitro cytotoxicity: role of biokinetic modelling. ALTEX $23 \mathrm{Sp}$. Issue, 250-253.

Bremer, S., Worth, A. P., Paparella, M. et al. (2001). Establishment of an in vitro reporter gene assay for developmental cardiac toxicity. Toxicol. In Vitro 15, 215-223.

Bremer, S., Pellizzer, C., Hoffmann, S. et al. (2007). The development of new concepts for assessing reproductive toxicity applicable to large scale toxicological programmes. Curr. Pharm. Des. 13(29), 3047-3058.

Broadhead, C. and Bottrill, K. (1997). Strategies for replacing animals in biomedical research. Mol. Med. Today 3(11), 483-487.

Brown, N. A. (1987). Teratogenicity testing in vitro: status of validation studies. Arch. Toxicol.Suppl. 11, 105-114.

Brown, N. A., Spielmann, H., Bechter, R. et al. (1995). Screening chemicals for reproductive toxicity: the current alternatives. ATLA 23, 868-882.

Brusick, D. J. (1977). In vitro mutagenesis assays as predictors of chemical carcinogenesis in mammals. Clin. Toxicol. 10, 79-109.

Buesen, R., Visan, A., Genschow, E. et al. (2004). Trends in improving the embryonic stem cell test (EST): an overview. ALTEX 21(1), 15-22.

Cahill, P. A., Knight, A. W., Billinton, N. et al. (2004). The GreenScreen genotoxicity assay: a screening validation programme. Mutagenesis 19, 105-119.

CDER, Center for Drug Evaluation and Research, US Department of Health and Human Services Food and Drug Administration (2006). Guidance for Industry, Investigators, and Reviewers: Exploratory IND Studies. Rockville, MD, US: CDER.

Charles, G. D. (2004). In vitro models in endocrine disruptor screening. ILAR J. 45(4), 494-501.

Collins F. S., Gray, G. M. and Bucher, J. R. (2008). Transforming environmental health protection. Science 319, 906907.

Comber, M. H., Walker, J. D., Watts, C. and Hermens, J. (2003). Quantitative structure-activity relationships for predicting potential ecological hazard of organic chemicals for use in regulatory risk assessments. Environ. Toxicol. Chem. 22, 1822-1828.

Combes, R., Balls, M., Curren, R. et al. (1999). Cell transformation assays as predictors of human carcinogenicity: The report and recommendations of ECVAM Workshop 39. ATLA 27, 745767.

Combes, R. D. (2000). The use of structure-activity relationships and markers of cell toxicity to detect non-genotoxic carcinogens. Toxicol. In Vitro 14, 387.

Combes, R. D., Berridge, T., Connelly, J. et al. (2003). Early microdose drug studies in human volunteers can minimise animal testing - proceedings of a workshop organised by Volunteers in Research and Testing. Eur. J. Pharm. Sci. 19, 1-11.

Combes, R. D., Balls, M., Bansil, L. et al. (2004). The Third FRAME Toxicity Committee: Working toward greater implementation of alternatives in toxicity testing. ATLA 32 Suppl. 1B, 635-642. 
Combes, R. (2007). Developing, validating and using test batteries and tiered (hierarchical) testing schemes. ATLA 35, 375-378.

Combes, R., Grindon, C., Cronin, M. T. et al. (2007). Proposed integrated decision-tree testing strategies for mutagenicity and carcinogenicity in relation to the EU REACH legislation. ATLA 35(2), 267-287.

Cone, J. E. and Rosenberg, J. (1990). Medical surveillance and biomonitoring for occupational cancer endpoints. Occup. Med. 5, 563-581.

Conolly, R. B., Reitz, R. H., Clewell, H. J. 3rd and Andersen, M. E. (1988). Pharmacokinetics, biochemical mechanism and mutation accumulation: a comprehensive model of chemical carcinogenesis. Toxicol. Lett. 43, 189-200.

Cosson, P. (2007). A non-mammalian system to study bacterial infections. $A L$ TEX 24 Sp. Issue, 78-79.

Council of Europe (1986). European Convention for the Protection of Vertebrate Animals Used for Experimental and Other Scientific Purposes (ETS 123). Strasbourg, France: Council of Europe.

Crespi, C. (1995). Xenobiotic-metabolizing human cells as tools for pharmacological and toxicological research. $A d v$. Drug Res. 26, 180-235.

Cronin, M. T., Dearden, J. C., Walker, J. D. and Worth, A. P. (2003). Quantitative structure-activity relationships for human health effects: commonalities with other endpoints. Environ. Toxicol. Chem. 22, 1829-1843.

Dearfield, K. L., Auletta, A. E., Cimino, M. C. and Moore, M. M. (1991). Considerations in the U.S. Environmental Protection Agency's testing approach for mutagenicity. Mutat. Res. 258, 259283.

Department of Health (DH) (UK): Committee on Mutagenicity of Chemicals in Food, Consumer Products and the Environment (2000). Guidance on a Strategy for Testing of Chemicals for Mutagenicity. London, UK: DH.

DiMasi, J. A., Hansen, R. W. and Grabowski, H. G. (2003). The price of innovation: new estimates of drug development costs. J. Health Econ. 22(2), 151-185.

EC (European Commission) (2003). IP/03/969. European Commission pro- poses strict ethical guidelines on EU funding of human embryonic stem cell research.

ECETOC (European Centre for Ecotoxicology and Toxicology of Chemicals) (1997). Aneuploidy: ECETOC Monograph No. 27. Brussels, Belgium: ECETOC.

ECHA (European Chemicals Agency) (2008). Guidance on Registration. Version 1.2. Helsinki, Finland: ECHA.

Eckert, J. (1997). Alternatives to animal experimentation in parasitology. Vet. Parasitol. 71(2-3), 99-120.

ECVAM (European Centre for the Validation of Alternative Methods), Joint Research Centre, European Commission Directorate General (undated). Validated methods. http://ecvam.jrc.it/, accessed 31. Aug. 2008.

Ellinger-Ziegelbauer, H., Gmuender, H., Bandenburg, A. and Ahr, H. J. (2008). Prediction of a carcinogenic potential of rat hepatocarcinogens using toxicogenomics analysis of short-term in vivo studies. Mutat. Res. 637(1-2), 23-39.

EPA (Environmental Protection Agency) (US). (2007). OncoLogic ${ }^{\mathrm{TM}}-A$ computer system to evaluate the carcinogenic potential of chemicals.

EPA (Environmental Protection Agency) (US). (Updated 20 Mar. 2008). High Production Volume (HPV) Challenge. http://www.epa.gov/HPV/, accessed 9 Jun. 2008.

Epstein, S. S. (1998). The Politics of Cancer Revisited. Fremont Center, NY, USA: East Ridge Press.

Farr, S. and Dunn, R. T. (1999). Concise review: gene expression applied to toxicology. Toxicol. Sci. 50, 1-9.

Fenner-Crisp, P. A., Maciorowski, A. F. and Timm, G. E. (2000). The endocrine disruptor screening program developed by the U.S. Environmental Protection Agency. Ecotoxicology 9(1-2), 85-91.

Fleischer, M. (2007). Testing cost and testing capacity according to $\mathrm{REACH}$ requirements - results of a survey of independent and corporate GLP laboratories in the EU and Switzerland. J. Business Chem. 4, 96-114.

Gallas, M. M., Abeleira, M. T., Fernandez, J. R. and Burguera, M. (2005). Threedimensional numerical simulation of dental implants as orthodontic anchorage. Eur. J. Orthod. 27, 12-16.
Genschow, E., Spielmann, H., Scholz, G. et al. (2002). The ECVAM international validation study on in vitro embryotoxicity tests: results of the definitive phase and evaluation of prediction models. ATLA 30(2), 151-176.

Genschow, E., Spielmann, H., Scholz, G. et al. (2004). Validation of the embryonic stem cell test in the international ECVAM validation study on three in vitro embryotoxicity tests. ATLA 32(3), 209-244.

Germani, M., Crivori, P., Rocchetti, M. et al. (2007). Evaluation of a basic physiologically based pharmacokinetic model for simulating the first-time-in-animal study. Eur. J. Pharm. Sci. 31(3-4), 190 201.

Gerner, I., Barratt, M. D., Zinke, S. et al. (2004). Development and prevalidation of a list of structure-activity relationship rules to be used in expert systems for prediction of the skin-sensitising properties of chemicals. ATLA 32(5), 487-509.

Gold, L. S., Manley, N. B., Slone, T. H. and Rohrbach, L. (1999). Supplement to the Carcinogenic Potency Database (CPDB): results of animal bioassays published in the general literature in 1993 to 1994 and by the National Toxicology Program in 1995 to 1996. Environ. Health Perspect. 107 Suppl. 4, 527-600.

Goodman, J. I. (2001). A perspective on current and future uses of alternative models for carcinogenicity testing. Toxicol. Pathol. 29 Suppl. 1, 173-176.

Green, S., Goldberg, A. M. and Zurlo, J. (2001). The TestSmart-HPV program: development of an integrated approach for testing high production volume chemicals. Regul. Toxicol. Pharmacol 33(2), 105-109.

Green, S. and Goldberg, A. M. (2004). TestSmart and toxic ignorance. ATLA 32 Suppl. 1A, 359-363.

Gruber, F. P. and Hartung, T. (2004). Alternatives to animal experimentation in basic research. ALTEX 21 Suppl. 1, 3-31.

Guengerich, F. P. (2006). Cytochrome P450s and other enzymes in drug metabolism and toxicity. AAPS J. 8(1), E101-E111.

Hartung, T. (2007). Food for thought ... on cell culture. ALTEX 24(3), 143-147. 
Hartung, T. (2008a). Food for thought ... on animal tests. ALTEX 25(1), 3-9.

Hartung, T. (2008b). Thoughts on limitations of animal models. Parkinsonism Relat. Disord., (in press).

Hartung, T. and Leist, M. (2008). Food for thought...on the evolution of toxicology and the phasing out of animal testing. ALTEX 25(2), 91-96.

Hastwell, P. W., Chai, L. L., Roberts, K. J. et al. (2006). High-specificity and high-sensitivity genotoxicity assessment in a human cell line: validation of the GreenScreen ${ }^{\circledR}$ HC GADD45a-GFP genotoxicity assay. Mutat. Res. 607, 160-175.

Heindl, C., Hess, A. and Brune, K. (2008). Refinement and reduction in animal experimentation: options for new imaging techniques. ALTEX 25(2), 121-125.

Hendriksen, C. F. (2006). Towards eliminating the use of animals for regulatory required vaccine quality control. $A L$ TEX 23(3), 187-90.

Huggins, J. (2003). Alternatives to animal testing: research, trends, validation, regulatory acceptance. ALTEX 20 Suppl. 1, 3-61.

Jennings, P., Koppelstaetter, C., Pfaller, W. et al. (2004). Assessment of a new cell culture perfusion apparatus for in vitro chronic toxicity testing. Part 2: Toxicological evaluation. ALTEX 21(2), 61-66.

Kirkland, D., Aardema, M., Henderson, L. and Muller, L. (2005). Evaluation of the ability of a battery of three in vitro genotoxicity tests to discriminate rodent carcinogens and non-carcinogens I. Sensitivity, specificity and relative predictivity. Mutat. Res. 584, 1-256.

Knight, A. (2007). Systematic reviews of animal experiments demonstrate poor human clinical and toxicological utility. ATLA 35(6), 641-659.

Knight,A. (2008). 127 million non-human vertebrates used worldwide for scientific purposes in 2005. ATLA 36, in press.

Knight, A., Bailey, J. and Balcombe, J. (2006a). Animal carcinogenicity studies: 3. alternatives to the bioassay. ATLA 34(1), 39-48.

Knight, A., Bailey, J. and Balcombe, J. (2006b). Animal carcinogenicity studies: 1. poor human predictivity. ATLA 34(1), 19-27.

Kolossov, E., Fleischmann, B. K., Liu, Q. et al. (1998). Functional characteristics of ES cell-derived cardiac precursor cells identified by tissue-specific expression of the green fluorescent protein. $J$. Cell. Biol. 143(7), 2045-2056.

Kramer, J. A., Curtiss, S. W., Kolaja, K. L. et al. (2004). Acute molecular markers of rodent hepatic carcinogenesis identified by transcription profiling. Chem. Res. Toxicol. 17, 463-470.

Kramer, B. S., Wilentz, J., Alexander, D. et al. (2006). Getting it right: being smarter about clinical trials: a major $\mathrm{NIH}$ meeing led to recommendations for conducting better clinical trials. PLoS Medicine 3, 144.

Kulpa-Eddy, J. A. (2006). Overview of the regulatory requirements for the consideration of alternatives. ALTEX $23 S p$. Issue, 200-202.

Landolph, R. A. (1985). Chemical transformation in $\mathrm{C} 3 \mathrm{H} 10 \mathrm{~T} 1 / 2 \mathrm{CCl} 18$ mouse embryo fibroblasts: historical background, assessment of transformation assay and evolution and optimization of the transformation assay protocol. In T. Kakunaga and H. Yamasaki (eds.), Transformation assay of established cell lines: Mechanisms and Application, IRAC Scientific Publications No. 67 (185-203). Lyon, France: Intnl. Agency for Res. on Cancer.

Langley, G., Harding, G., Hawkins, P. et al. (2000). Volunteer studies replacing animal experiments in brain research: report and recommendations of a volunteers in research and testing workshop. ATLA 28, 315-331.

Langley, G., Evans, T., Holgate, S. T. and Jones, A. (2007). Replacing animal experiments: choices, chances and challenges. BioEssays 29(9), 918-926.

Langsch, A. and Nau, H. (2006). Metabolic activation for in vitro systems. ALTEX 23 Sp. Issue, 353-357.

Larson, J. A. (2006). The animal welfare information center: helping the community meet the information requirement of the 3Rs. ALTEX $23 \mathrm{Sp}$. Issue, 192-196.

Lavé, T., Parrott, N., Grimm, H. P. et al. (2007). Challenges and opportunities with modelling and simulation in drug discovery and drug development. Xenobiotica 37(10-11), 1295-1310.

Lazarou, J. and Pomeranz, B. (1998). Incidence of adverse drug reactions in hospitalized patients: a meta-analysis of prospective studies. J. Amer. Med. Assoc. 279, 1200-1205.

Leib, S. L. (2007). An in vitro model of central nervous system infection and regeneration: neuronal stem cells as targets of brain damage and regenerative therapies in bacterial meningitis. $A L$ TEX 24 Sp. Issue, 90-92.

Leist, M., Kadereit, S. and Schildknecht, S. (2008a). Food for thought ... on the real success of $3 \mathrm{R}$ approches. ALTEX 25(1), 17-24.

Leist, M., Hartung, T. and Nicotera, P. (2008b). The dawning of a new age of toxicology. ALTEX 25(2), 103-114.

Li, A. P. (2005). Cell culture tool and method. U.S. Patent 20050101010.

Li, A. P. (2008a). Human hepatocytes as an effective alternative experimental system for the evaluation of human drug properties: general concepts and assay procedures. ALTEX 25(1), 33-42.

Li, A. P. (2008b). In vitro evaluation of human xenobiotic toxicity: scientific concepts and the novel integrated discrete multiple cell coculture (IdMOC) technology. ALTEX 25(1), 43-49.

Lichtenberg-Frate, H., Schmitt, M., Gellert, G. and Ludwig, J. (2003). A yeastbased method for the detection of cytoand genotoxicity. Toxicol. In Vitro 17, 709-716.

Lilienblum, W., Dekant, W., Foth, H. et al. (2008). Alternative methods to safety studies in experimental animals: role in the risk assessment of chemicals under the new European Chemicals Legislation (REACH). Arch. Toxicol. 82(4), 211-236.

Lockhart, D. J. and Winzeler, E. A. (2000). Genomics, gene expression and DNA arrays. Nature 405, 827-836.

Louekari, K., Sihvonen, K., Kuittinen, M. and Sømnes, V. (2006). In vitro tests within the REACH information strategies. ATLA 34(4), 377-386.

Luttun, A. and Verfaillie, C. M. (2006). A perspective on stem cells as a tool for in vitro testing. ALTEX 23 Sp. Issue, 388392.

Mackerle, J. (2004). Finite element modelling and simulations in dentistry: a bibliography 1990-2003. Comp. Methods Biomech. Biomed. Eng. 7, 277-303.

MAP Coalition, Mandatory Alternatives Petition Coalition (2007). Petition to the 
US Food and Drug Administration for Mandatory Use of Non-Animal Methods in the Development and Approval of Drugs and Devices.

Matthews, E. J. and Contrera, J. F. (1998). A new highly specific method for predicting the carcinogenic potential of pharmaceuticals in rodents using enhanced MCASE QSAR-ES software. Regul. Toxicol. and Pharmacol. 28, 242-264.

Matthews, R. A. (2008). Medical progress depends on animal models - doesn't it? J.R. Soc. Med. 101, 95-98.

Mauthe, R. J., Gibson, D. P., Bunch, R. T. and Custer, L. (2001). The Syrian hamster embryo (SHE) cell transformation assay: review of the methods and results. Toxicol. Pathol. 29 Suppl. 1, 138-146.

Metzger, J. M., Lin, W. I. and Samuelson, L. C. (1996). Vital staining of cardiac myocytes during embryonic stem cell cardiogenesis in vitro. Circ. Res. 78, 547-552.

MHRA, Medicines and Healthcare products Regulatory Agency (2006). Investigator's Brochure: TGN1412 humanized agonistic anti-CD28 monoclonal antibody. http://www.mhra.gov.uk/home/ groups/es-foi/documents/foidisclosure/ con2023525.pdf, accessed 9 Jun. 2008.

Mitchell, I. de G. and Combes, R. D. (1997). In vitro genotoxicity and cell transformation assessment. In J.V. Castell and M.J. Gómez-Lechón (eds.), In Vitro Methods in Pharmaceutical Research (318-352). London, UK: Academic Press.

Mitterhauser, M. and Toegel, S. (2008). An in vitro model for the comparative evaluation of bone seeking pharmaceuticals. ALTEX 25(1), 51-55.

Monro, A. M. and MacDonald, J. S. (1998). Evaluation of the carcinogenic potential of pharmaceuticals. Opportunities arising from the International Conference on Harmonisation. Drug Safety 18, 309-319.

Montag, T., Spreitzer, I., Löschner, B. et al. (2007). Safety testing of cell-based medicinal products: opportunities for the monocyte activation test for pyrogens. ALTEX 24(2), 81-89.

Morton, D. B. (1995). Advances in refinement in animal experimentation over the past 25 years. ATLA 23, 812-822.
Morton, D. B. (1998). ANZCCART Facts Sheet. The importance of non-statistical design in refining animal experimentation. ANZCCART News 11(2), 12. Glen Osmond, SA, Australia: ANZCCART.

Murthy, B. (2007). Relevance of in vitro toxicology studies in risk assessment. ALTEX 24(3), 174-177.

Nahmias, Y. K., Gao, B. Z. and Odde, D. J. (2004). Dimensionless parameters for the design of optical traps and laser guidance systems. Appl. Opt. 43, 39994006.

NIH (National Institutes of Health) (2006). Information on clinical trials and human research studies.

Northwick Park Hospital (2006). Press Statement from Northwick Park Hospital, 5 April 2006.

NRC (National Research Council) (US) (2007). Toxicity Testing in the 21st Century: A Vision and a Strategy. Washington, DC, US: National Academies Press.

NTP (National Toxicology Program) (US) (2004). A National Toxicology Program for the 21st Century: A Roadmap for the Future. NC, US: NTP, National Institute of Environmental Health Sciences.

O'Connor, A. M. (1997). Barriers to regulatory acceptance. In L. F. M. van Zutphen and M. Balls (eds.), Animal Alternatives, Welfare and Ethics (11731176). Amsterdam, The Netherlands: Elsevier.

Odde, D. J. and Renn, M. J. (2000). Laserguided direct writing of living cells. Biotechnol. Bioeng. 67, 312-318.

Paparella, M., Kolossov, E., Fleischmann, B. K. et al. (2002). The use of quantitative image analysis in the assessment of in vitro embryotoxicity endpoints based on a novel embryonic stem cell clone with endoderm-related GFP expression. Toxicol. In Vitro 16(5), 589-597.

Parry, E. M. and Parry, J. M. (1995). In vitro cytogenetics and aneuploidy. In D.H. Phillips and S. Venitt (eds.), Environmental Mutagenesis (121-139). Oxford, UK: Bios Scientific Publishers.

Pellizzer, C., Adler, S., Corvi, R. et al. (2004a). Monitoring of teratogenic effects in vitro by analysing a selected gene expression pattern. Toxicol. In Vitro 18(3), 325-335.

Pellizzer, C., Bello, E., Adler, S. et al. (2004b). Detection of tissue specific effects by methotrexate on differentiating mouse embryonic stem cells. Birth Defects Res. B. Dev. Reprod. Toxicol. 71(5), 331-341.

Pellizzer, C., Bremer, S. and Hartung, T. (2005). Developmental toxicity testing from animal towards embryonic stem cells. ALTEX 22(2), 47-57.

Pichler, W. J. (2007). Predicting drug hypersensitivity by in vitro tests. ALTEX 24 Sp. Issue, 49-52.

Pienta, R. J., Poiley, J. A. and Lebherz, W. B. 3rd (1977). Morphological transformation of early passage golden Syrian hamster embryo cells derived from cryopreserved primary cultures as a reliable in vitro bioassay for identifying diverse carcinogens. Int. J. Cancer 19, 642-655.

Pippin, J. J. (2008). “MAP” for improving drug testing: Mandatory Alternatives Petition urges FDA to require use of replacements to animal testing. Genetic Engineering and Biotechnology News, 28(5).

Purcell, W. M. and Atterwill, C. K. (1995). Mast cells in neuroimmune function: neurotoxicological and neuropharmacological perspectives. Neurochem. Res. 20, 521-532.

Reznikoff, T., Bertram, J. S., Brankow, D. W. and Heidelberger, C. (1973). Quantitative and qualitative studies on chemical transformation of cloned $\mathrm{C} 3 \mathrm{H}$ mouse embryo cells sensitive to postconfluence inhibition of cell division. Cancer Res. 33, 3239-3249.

Robinson, S., Delongeas, J.-L., Donald, E. et al. (2008). A European pharmaceutical company initiative challenging the regulatory requirement for acute toxicity studies in pharmaceutical drug development. Regul. Toxicol. Pharmacol. 50,345-352.

Rowan, A. N. (1995). The third R: refinement. ATLA 23, 332-346.

Russell, W. M. S. and Burch, R. L. (1959). The Principles of Humane Experimental Technique. London, UK: Methuen.

Sandusky, C. B., Even, M., Stoick, K. and Sandler, J. (2006). Strategies to reduce animal testing in US EPA's HPV programme. ALTEX 23 Sp. Issue, 150-152.

Schindler, S., Spreitzer, I., Löschner, B. et al. (2006a). International validation of pyrogen tests based on cryopreserved human primary blood cells. J. Immunol. 
Methods 316(1-2), 42-51.

Schindler, S., Rosenberg, U., Schlote, D. et al. (2006b). Pyrogen testing of lipidic parenterals with a novel in vitro test: application of the IPT based on cryopreserved human whole blood. Pharmeur. Sci. Notes 1, 1-7.

Schindler, S., Fennrich, S., Crameri, R. et al. (2007). Fever in the test tube: towards a human(e) pyrogen test. ALTEX 24 Sp. Issue, 60-62.

Schrattenholz, A. and Klemm, M. (2007). Neuronal cell culture from human embryonic stem cells as in vitro model for neuroprotection. ALTEX 24(1), 9-15.

Schriefer, T. N., Mills, K. R., Murray, N. M. and Hess, C. W. (1988). Evaluation of proximal facial nerve conduction by transcranial magnetic stimulation. $J$. Neurol. Neurosurg. Psychiat. 51, 6066.

Scialli, A. R. (2008). The challenge of reproductive and developmental toxicology under REACH. Regul. Toxicol. Pharmacol.51(2), 244-250.

Seiler, A., Visan, A., Pohl, I. et al. (2002). Improving the embryonic stem cell test (EST) by establishing molecular endpoints of tissue specific development using murine embryonic stem cells (D3 cells). ALTEX 19 Suppl. 1, 55-63.

Seiler, A., Visan, A., Buesen, R. et al. (2004). Improvement of an in vitro stem cell assay for developmental toxicity: the use of molecular endpoints in the embryonic stem cell test. Reprod. Toxicol. 18(2), 231-240.

Silliman, C. C. and Wang, M. (2006). The merits of in vitro versus in vivo modelling in investigation of the immune system. Environ. Toxicol. Pharmacol. 21(2), 123-134.

Stephens, M. L., Alvino, G. M. and Branson, J. B. (2002). Animal pain and distress in vaccine testing in the United States. Dev. Biol. (Basel) 111, 213-216.

Stokes, W. S. (2004). Selecting appropriate animal models and experimental designs for endocrine disruptor research and testing studies. ILAR J. 45(4), 387393.
Taylor, K., Gordon, N., Langley, G. and Higgins, W. (2008). Estimates for worldwide laboratory animal use in 2005. ATLA 36, 327-342.

Tennant, R. W., Spalding, J., Stasiewicz, S. and Ashby, J. (1990). Prediction of the outcome of rodent carcinogenicity bioassays currently being conducted on 44 chemicals by the National Toxicology Program. Mutagenesis 5, 3-14.

Tsuchiya, T. and Umeda, M. (1995). Improvement in the efficiency of the in vitro transformation assay method using BALB/3T3 A31-1-1 cells. Carcinogenesis 16, 1887-1894.

Tsuchiya, T., Umeda, M., Nishiyama, H. et al. (1999). An interlaboratory validation study of the improved transformation assay employing Balb/c 3T3 cells: results of a collaborative study on the two-stage cell transformation assay by the Nongenotoxic Carcinogen Study Group. ATLA 27, 685-702.

Ullrich, A., Berg, C., Hengstler, J. G. and Runge, D. (2007). Use of a standardised and validated long-term human hepatocyte culture system for repetitive analyses of drugs: repeated administrations of acetaminophen reduces albumin and urea secretion. ALTEX 24(1), 35-40.

USDA-APHIS-AC, US Department of Agriculture-Animal and Plant Health Inspection Service-Animal Care (2000). Animal Care Survey: USDA Employee Survey on the Effectiveness of IACUC Regulations. Riverdale, MD, US: USDA-APHIS-AC.

US Government Printing Office (1985). The Animal Welfare Act-As Amended. Known as the "Improved Standards for Laboratory Animal" 7 US Code \$2131-2159. Public Law 99-198 7Code of Federal Regulations2.22, 2.80, and $371.2(\mathrm{~g})$. Washington, DC, US: U.S. Government Printing Office.

Vedani, A., Dobler, M. and Lill, M. A. (2005). Virtual test kits for predicting harmful effects triggered by drugs and chemicals mediated by specific proteins. ALTEX 22(3), 123-134.

Vedani, A., Lill, M. A. and Dobler, M. (2007a). Predicting the toxic potential of drugs and chemicals in silico. ALTEX 24 Sp. Issue, 63-66.

Vedani, A., Dobler, M., Spreafico, M. et al. (2007b). VirtualToxLab - in silico prediction of the toxic potential of drugs and environmental chemicals: evaluation status and internet access protocol. ALTEX 24(3), 153-161.

Veith, G. D. (2006). Roles for QSAR in risk assessment. ALTEX 23 Sp. Issue, 369-372.

Weibel, F., Andersson, T., Casciano, D. et al. (1997). Genetically engineered cell lines: characterisation and applications in toxicity testing. The Report and Recommendations of ECVAM Workshop 26. ATLA 25, 625-639.

Whitlow, S., Bürgin, H. and Clemann, N. (2007). The Embryonic Stem Cell Test for the early selection of pharmaceutical compounds. ALTEX 24(1), 3-7.

Wishart, D. S. (2007). Improving early drug discovery through ADME modelling: an overview. Drugs R. D. 8(6), 349-362.

Worth, A. P. and Balls, M. (eds.) (2002). Alternative (non-animal) methods for chemicals testing: current status and future prospects. A report prepared by ECVAM and the ECVAM Working Group on Chemicals. ATLA 30 Suppl. 1, 1-125.

Zhang, H., Borman, H. D. and Myhr, B. C. (2004). Enhancement of the morphological transformation of Syrian hamster embryo (SHE) cells by reducing incubation time of the target cells. Mutat. Res. 548, 1-7.

\section{Correspondence to}

Andrew Knight BSc., BVMS, CertAW, MRCVS

Director

Animal Consultants International

91 Vanbrugh Ct.

Wincott St.

London SE11 4NR

UK

www.AnimalConsultants.org 